\title{
Toxicology of silica nanoparticles: an update
}

\author{
Sivakumar Murugadoss ${ }^{1} \cdot$ Dominique Lison $^{2} \cdot$ Lode Godderis $^{3}$. \\ Sybille Van Den Brule ${ }^{2} \cdot$ Jan Mast $^{4} \cdot$ Frederic Brassinne $^{4}$. \\ Noham Sebaihi $^{5} \cdot$ Peter H. Hoet $^{1}$ (D)
}

Received: 8 May 2017 / Accepted: 18 May 2017 / Published online: 1 June 2017

(C) The Author(s) 2017. This article is an open access publication

\begin{abstract}
Large-scale production and use of amorphous silica nanoparticles (SiNPs) have increased the risk of human exposure to SiNPs, while their health effects remain unclear. In this review, scientific papers from 2010 to 2016 were systematically selected and sorted based on in vitro and in vivo studies: to provide an update on SiNPs toxicity and to address the knowledge gaps indicated in the review of Napierska (Part Fibre Toxicol 7:39, 2010). Toxicity of SiNPs in vitro is size, dose, and cell type dependent. SiNPs synthesized by wet route exhibited noticeably different biological effects compared to thermal route-based SiNPs. Amorphous SiNPs (particularly colloidal and stöber) induced toxicity via mechanisms similar to crystalline silica. In vivo, route of administration and physicochemical properties of SiNPs influences the toxicokinetics. Adverse effects were mainly observed in acutely exposed animals, while no significant signs of toxicity were noted in
\end{abstract}

Peter H. Hoet

peter.hoet@kuleuven.be

Sivakumar Murugadoss

sivakumar.murugadoss@kuleuven.be

Dominique Lison

dominique.lison@uclouvain.be

Lode Godderis

lode.godderis@kuleuven.be

Sybille Van Den Brule

sybille.vandenbrule@uclouvain.be

Jan Mast

jan.mast@coda-cerva.be

Frederic Brassinne

Frederic.Brassinne@coda-cerva.be

Noham Sebaihi

noham.sebaihi@economie.fgov.be chronically dosed animals. The correlation between in vitro and in vivo toxicity remains less well established mainly due to improper-unrealistic-dosing both in vitro and in vivo. In conclusion, notwithstanding the multiple studies published in recent years, unambiguous linking of physicochemical properties of SiNPs types to toxicity, bioavailability, or human health effects is not yet possible.

Keywords Amorphous silica nanoparticles · Pyrogenic . Colloidal $\cdot$ Stöber $\cdot$ Oxidative stress $\cdot$ Toxicity

\section{Introduction}

Nanosilica, also known as the nanoform $(<100 \mathrm{~nm})$ of silicon dioxide or silica nanoparticles (SiNPs), possesses distinct physico-chemical characteristics compared to its bulk

1 Unit for Lung Toxicology, Katholieke Universiteit Leuven, Herestraat 49, O\&N1, Room: 07.702, box 706, 3000 Louvain, Belgium

2 Louvain Centre for Toxicology and Applied Pharmacology (LTAP), Université Catholique de Louvain, Avenue E. Mounier 52/B1.52.12, 1200 Brussels, Belgium

3 Department of Occupational, Environmental and Insurance Medicine, Katholieke Universiteit Leuven, Kapucijnenvoer 35 block d, box 7001, 3000 Louvain, Belgium

4 EM-unit, Center for Veterinary and Agrochemical Studies and Research (CODA-CERVA), Groeselenberg 99, Uccle, 1180 Brussels, Belgium

5 General Quality and Safety, Metrology Department, National Standards, North Gate-Office 2A29, Bd du Roi Albert II, 16, 1000 Brussels, Belgium 
form; smaller size materials have an increased surface-tovolume ratio and a higher surface reactivity (Oberdörster 2010; Napierska et al. 2010). Due to their appealing properties, SiNPs are now extensively used in agriculture, food, and consumer products including cosmetics (Napierska et al. 2010; Khot et al. 2012; Kasaai 2015; Brinch et al. 2016). Until 2012, nearly 1.5 million tons of SiNPs had already been placed in the global market (Liljenström et al. 2013) and SiNPs became one of the three most produced nanomaterials (NMs) worldwide in 2013. Among the 846 nano-based products listed in a consumer products inventory, approximately 100 claim to contain SiNPs (Vance et al. 2015). Moreover, amorphous SiNPs are being synthesized with highly tunable biocompatibility and stability, and considered as a very promising candidate for various bio-medical applications such as gene carrier, drug delivery, and molecular imaging (Tang and Cheng 2013; Bitar et al. 2012).

In recent years, large-scale industrial production and global commercialization of SiNPs have resulted in increased risk of human exposures at workplaces (Kim et al. 2014a; Oh et al. 2014). Food additive silica (E551) is also in the nano size range (Dekkers et al. 2011), indicating that the general population is probably more exposed than initially anticipated. Moreover, in view of the efforts to use NM in medical applications, SiNPs could also be intentionally introduced into the human body for disease diagnosis and treatments (Croissant et al. 2017). Such growing potentials for exposure raised a global concern regarding the safety and potential adverse health effects of SiNPs.

Human health effects associated with silica exposure, especially crystalline silica $(0.5-10 \mu \mathrm{m})$, have widely been studied. Occupational exposure to crystalline silica induces silicosis in workers (a fibrotic lung disease) and is also associated with lung cancer, emphysema, and pulmonary tuberculosis (Leung et al. 2012). Conversely, natural amorphous silica is generally considered as less harmful, since the toxicological potential of silica has so far been linked to its crystallinity. Recent studies have revealed that amorphous SiNPs can be as reactive as crystalline particles (Turci et al. 2016). In vivo, amorphous SiNPs are, however, cleared more rapidly from the lung, which may contribute to explain their lower pathogenic potential (Arts et al. 2007). The human health effects of nanosilica remain to be clarified and toxicologists believe that exposure to SiNPs, due to their small size, may bring different adverse effects compared to micron-sized silica (Napierska et al. 2010).

The comprehensive review of Napierska et al. (2010) suggested that exposure to SiNPs $(1-100 \mathrm{~nm})$ induced toxic effects in vitro (immortalized mammalian cell lines) and in vivo (rats and mice). Physico-chemical properties such as size, surface area, and surface features were found to play a key role in the toxicity of SiNPs. Importantly, Napierska concluded that physico-chemical properties of SiNPs differ based on their production method and, therefore, may cause different biological effects. However, no definite conclusions were made due to insufficient or no data available for,

- Detailed physico-chemical characterization of different types of SiNPs;

- Comparison of the toxicity of different types of SiNPs (based on their production process);

- Comparison of the toxicity mechanisms of amorphous SiNPs and crystalline silica;

- Exposure via different routes and adverse effects of chronic exposure in vivo;

- Correlation of in vitro and in vivo studies and

- Physico-chemical properties for the safer design of SiNPs.

Therefore, the aim of this review is to summarize the toxicity studies of SiNPs published after the Napierska review (2010), critically discuss the outcomes, and to evaluate how these data gaps have been addressed (Fig. 1).

\section{Methodology}

The selection criteria was similar to the method described in Vriens et al. (2017), which was used to construct the MOD-ENP-TOX nanotoxicity database.

\section{Exclusion criteria}

To specifically focus on adverse health effects of SiNPs, papers reporting on other interventions such as ecotoxicity, synergistic effects, SiNPs doped with other materials, and therapy-based outcomes were excluded.

\section{Inclusion criteria}

Papers reporting,

1. physico-chemical characteristics such as primary size, shape, composition, and crystallinity;

2. toxicological endpoints such as cytotoxicity, apoptosis/ necrosis, genotoxicity, oxidative stress, immunotoxicity, and autophagy using immortalized cell lines or primary cells (experimental in vitro studies); and

3. toxic effects in laboratory-animals, more specifically in vivo experiments using rats and mice.

\section{Literature search}

We searched two databases for papers published from June 2010 (after Napierska et al. 2010) to December 2016. In 
Fig. 1 Systematic selection of studies

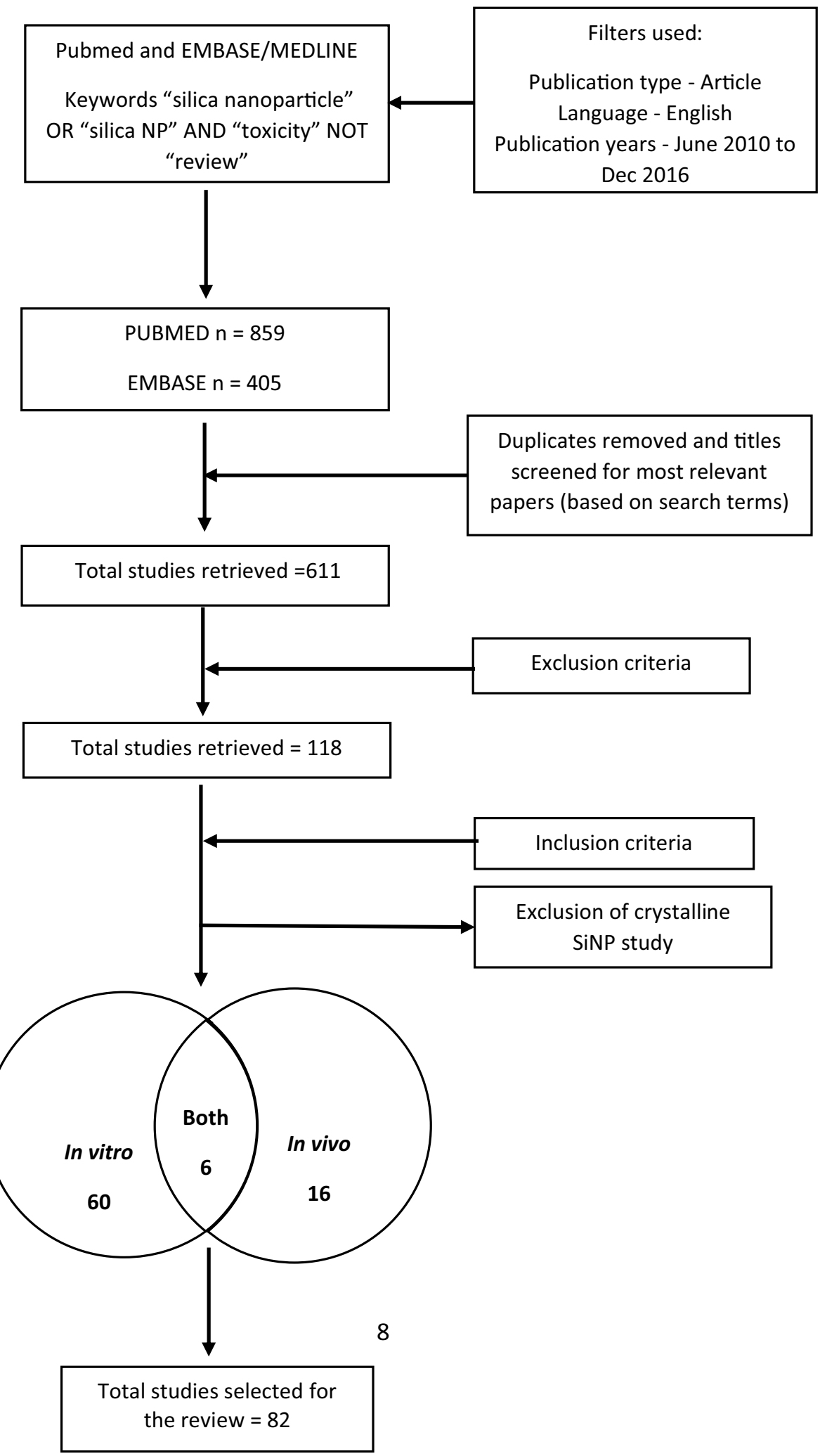

the PubMed "http://www.ncbi.nlm.nih.gov/PubMed" and EMBASE "https://www.embase.com" databases, the following keyword combinations were used: "silica nanoparticle" OR "silica NP" AND "toxicity" NOT "review". We retrieved a list of 859 and 405 articles in English, respectively. In a second step, duplicates were removed and the titles were screened to identify studies that best matched with our search terms, leaving 611 relevant papers. In a 
third step, we excluded papers that met the exclusion criteria and left 128 most relevant papers. Finally, 82 papers reporting a minimum set of physico-chemical characterization and toxic effects were selected for the main content of the review. Notably, only one study was found on the toxicity of crystalline nanosilica (Chu et al. 2012), but it was finally excluded due to insufficient data on the size of particles. As a result, the review is dealing only with amorphous SiNPs.

Induction of oxidative stress is considered as the major mechanism involved in SiNPs toxicity (Wang et al. 2009; Ye et al. 2010a, b) and, therefore, the in vitro section of the review was structured according to toxic endpoints and its association with oxidative stress. For in vivo, studies were sorted based on exposure route and modalities, since they can significantly influence the toxicokinetics of SiNPs. Throughout the review, the following abbreviations were used to indicate the different types of silica nanoparticles: SiNPs when it is not clear which type was used, C-SiNPs for colloidal silica; S-SiNP for stöber silica; M-SiNPs for mesoporous silica; Pr-SiNPs for precipitated silica; and PySiNPs for pyrogenic silica.

The table summarizing in vitro studies (Table 1) was sorted according to the type of SiNPs (colloidal, stöber, mesoporous, pyrogenic, precipitated, and not specified) and cell types. Table 2 (in vivo studies) was organized according to the type of SiNPs and exposure routes.

\section{In vitro studies}

\section{Cytotoxicity}

Oxidative stress (over production of reactive oxygen species, i.e., ROS) induced by NPs could damage the cellular components and lead to cell death via apoptosis (Fu et al. 2013). Therefore, studies reporting on cytotoxicity and oxidative stress were summarized in this section.

\section{Cytotoxicity associated with oxidative stress}

Duan et al. (2013a) showed that S-SiNPs $(62 \mathrm{~nm})$ induced time- $(6,12$, and $24 \mathrm{~h})$ and dose-dependent $(25-100 \mu \mathrm{g} / \mathrm{ml})$ reduction in cell viability (assessed by 3-(4,5-dimethylthiazol-2-Yl)-2,5-diphenyltetrazolium bromide, i.e., MTT), loss of membrane integrity (lactate dehydrogenase (LDH) release) and apoptosis (Annexin V/PI staining) in human umbilical vein endothelial cells (HUVECs). Apoptosis was also induced in lung (A549) and skin epithelial cells (A431) treated with Pr-SiNPs $(15 \mathrm{~nm})$. A dose-dependent increase $(25-200 \mu \mathrm{g} / \mathrm{ml}$ for $72 \mathrm{~h}$ ) in cytotoxicity (MTT and LDH), ROS production (assessed by dichlorodihydrofluorescein assay, i.e., DCFH-DA), lipid peroxidation (measurement of malondialdehyde, i.e., MDA), and apoptosis (caspase 3 and 9 activity) was observed in both cell lines. The lung cells showed, in general, a slightly higher toxic response compared to skin cells (Ahamed 2013).

SiNPs (20 and $80 \mathrm{~nm}$ ) induced P53-mediated apoptosis in human fetal lung fibroblasts (HFL-1). At the dose of $500 \mu \mathrm{g} / \mathrm{ml}, 20 \mathrm{~nm}$ SiNPs induced a threefold increase in DCF fluorescence compared to $80 \mathrm{~nm}$. In addition, increased expression of P53, upregulation of cytochrome C $(\mathrm{CytC})$ and caspase 9, and downregulation of anti-apoptotic protein B-cell lymphoma 2 (bcl2) was observed in cells treated with $1000 \mu \mathrm{g} / \mathrm{ml}$ for $48 \mathrm{~h}$ (Xu et al. 2012). Another study with lung fibroblasts also showed that SiNPs $(20 \mathrm{~nm})$ could reduce cell viability (MTT) by inducing apoptotic cell death (fluorescence microscopy) in a dose-dependent manner (250-1000 $\mu \mathrm{g} / \mathrm{ml}$ for $48 \mathrm{~h}$ ) (Zhang et al. 2011). Athinarayanan et al. (2014) isolated SiNPs $(10-50 \mathrm{~nm})$ from commercial food products processed with food additive silica (E551) and exposed human lung fibroblasts (WI38 cell line) with increasing doses $(25-400 \mu \mathrm{g} / \mathrm{ml})$. After $24 \mathrm{~h}$, they observed cytotoxicity (MTT) in a dose-dependent manner and ROS production (DCFH-DA) at $50 \mu \mathrm{g} / \mathrm{ml}$.

\section{Cytotoxicity not associated with oxidative stress}

Py-SiNPs (12 and $40 \mathrm{~nm}$ ) induced a significant size and dose- $\left(31.3,93.8\right.$, and $156.3 \mu \mathrm{g} / \mathrm{cm}^{2}$ culture well) dependent cytotoxicity (LDH, Sulphorodhamine B assay (SRB) and water-soluble tetrazolium-1(WST-1)) in human colon carcinoma cell line (HT29), while no induction of ROS (DCFH-DA) was observed (Gehrke et al. 2013). In the study by Napierska et al. (2012a), $50 \mu \mathrm{g} / \mathrm{ml}(24 \mathrm{~h})$ of $16 \mathrm{~nm}$ iron-doped S-SiNPs and pure S-SiNPs induced strong cytotoxicity (MTT and LDH) in a human endothelial cell line (EA.hy926), but a significant increase in oxidative stress markers [GSH depletion, malondialdehyde (MDA formation), induction of heme oxygenase-1, glutathione reductase, and NADPH oxidase-1] was observed only for iron-doped SiNPs.

\section{Conclusion: cytotoxicity}

Cytotoxicity of SiNPs was investigated using different cell lines and incubation times, making the comparison between studies difficult. However, from Table 3, it is clear that all types of SiNPs induced cytotoxicity. Significant (compared to untreated cells) cytotoxic effects were observed only at or above the concentration of $25 \mu \mathrm{g} / \mathrm{ml}$. Furthermore, it can be clearly seen that SiNPs induced oxidative stress and mediated apoptosis mainly via the intrinsic or mitochondrial pathway (caspase-dependent pathway) in a size- and dose-dependent manner. ROS-mediated toxicity is believed to be an important mechanism of NP toxicity 


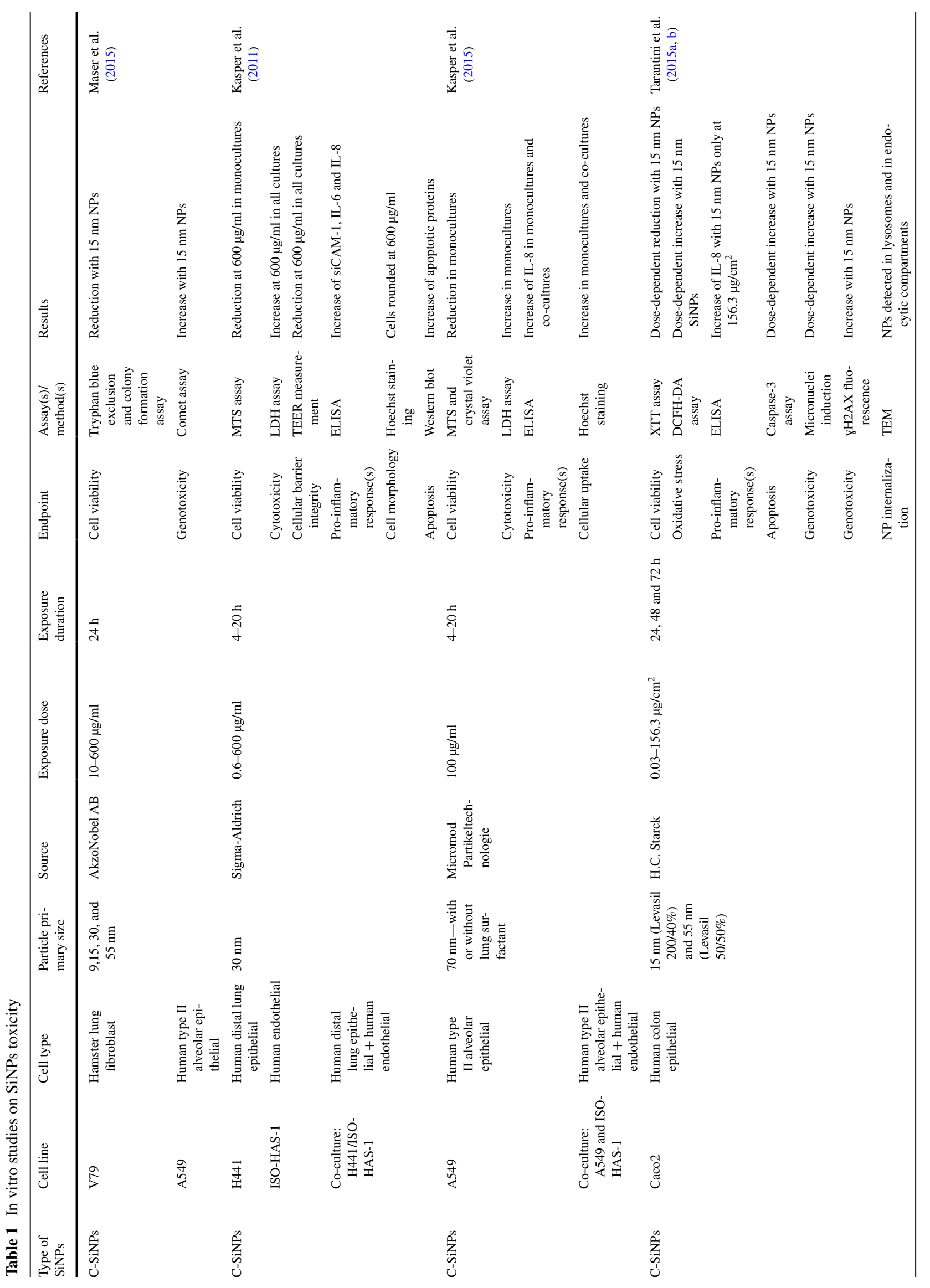




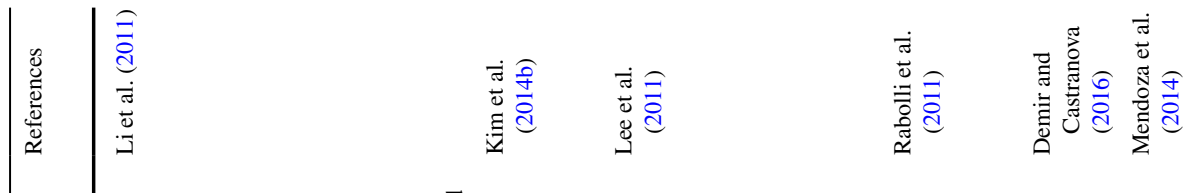

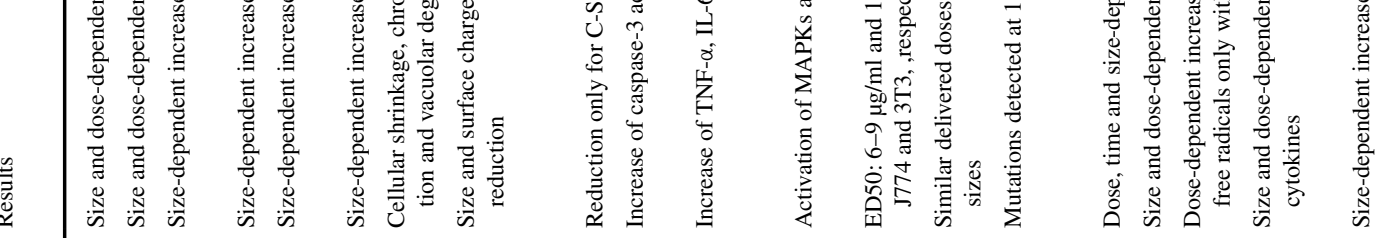

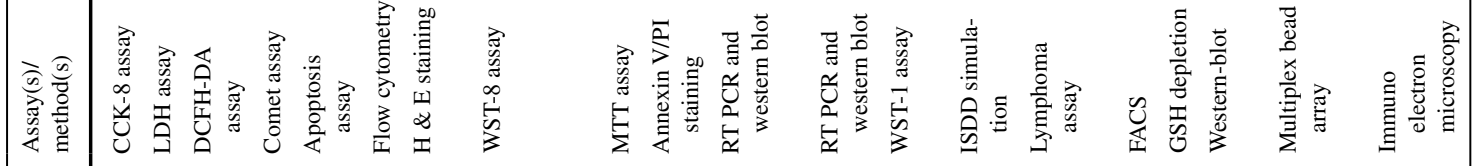

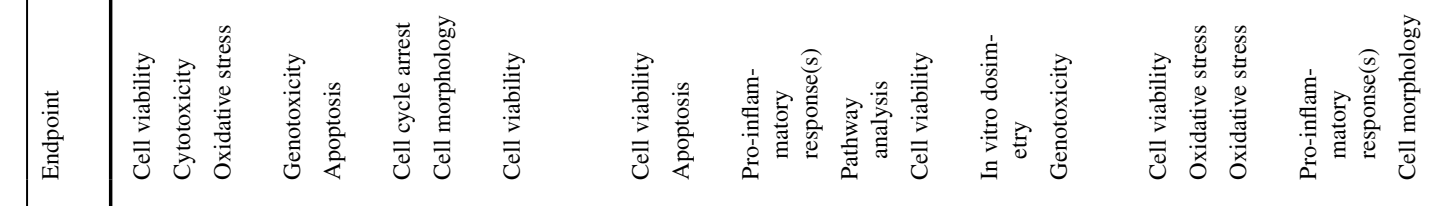

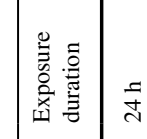

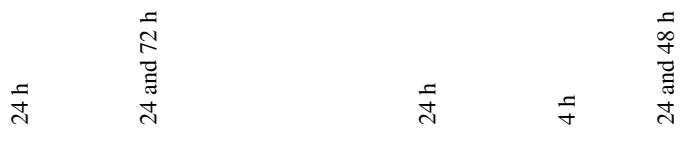

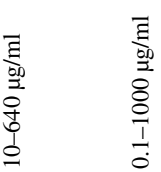

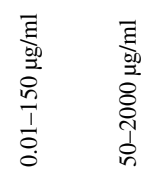

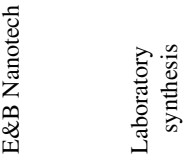

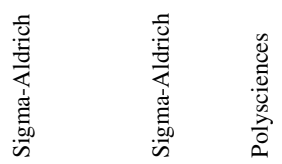

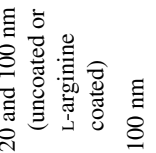

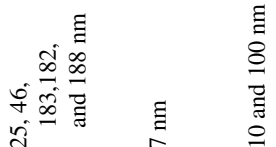

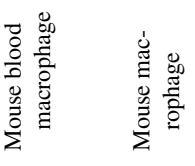

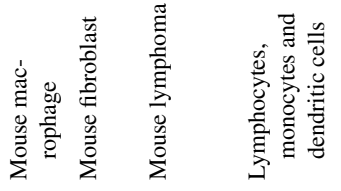

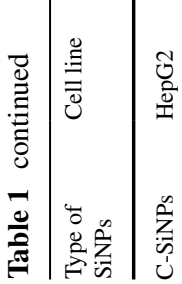

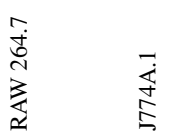

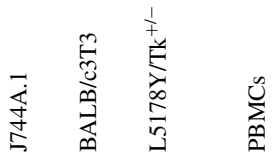

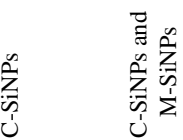

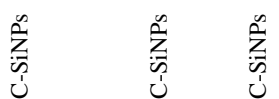




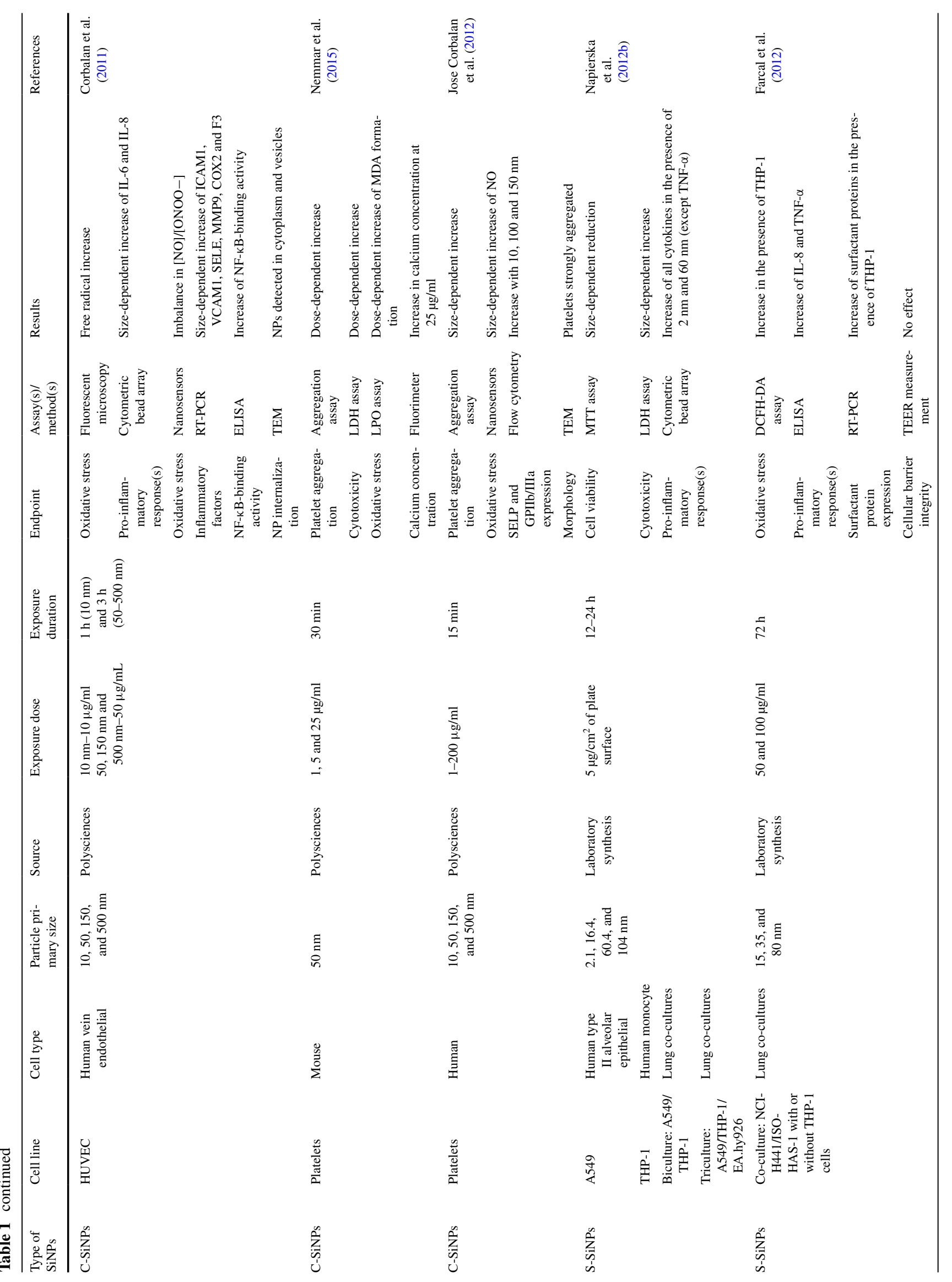




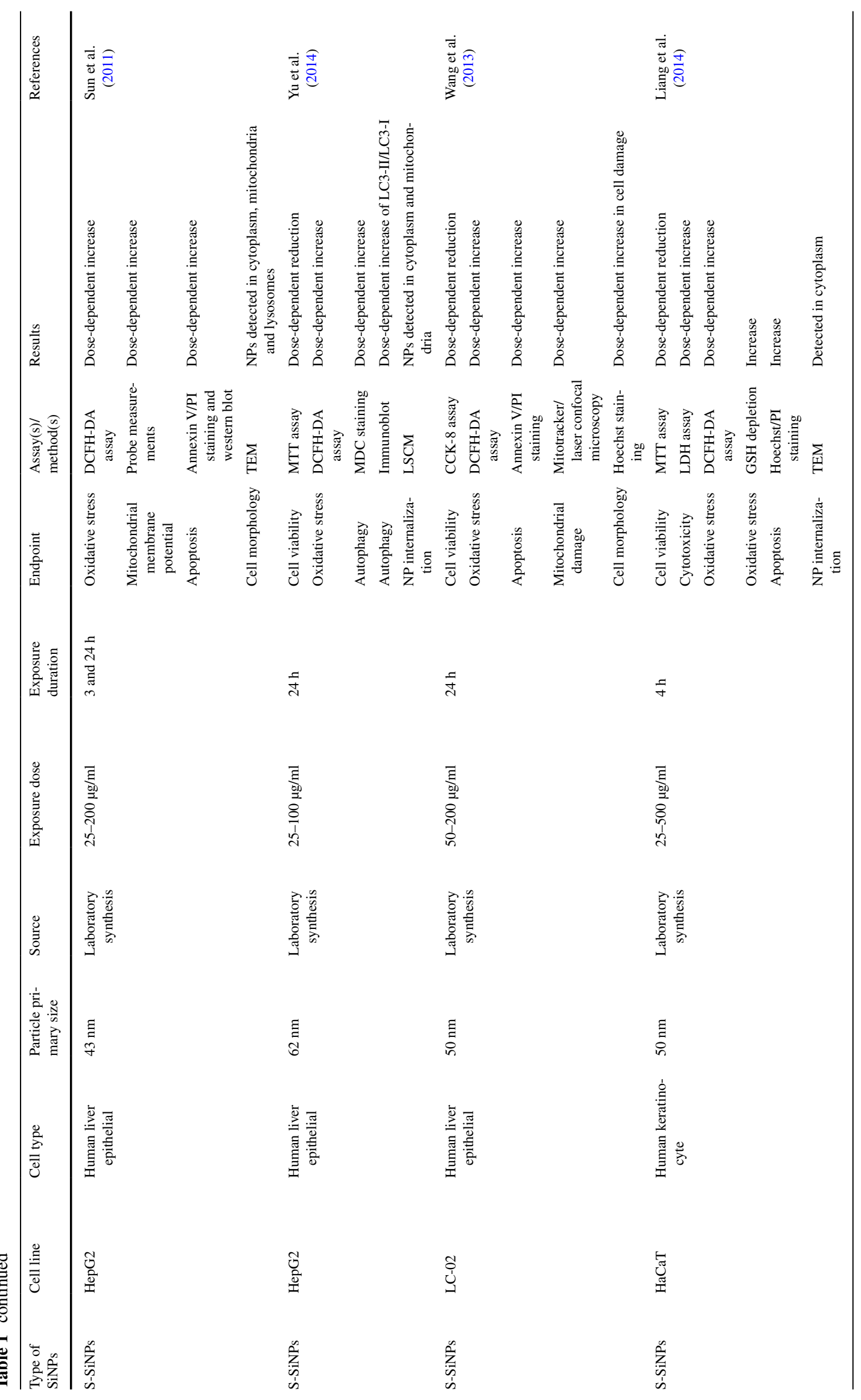




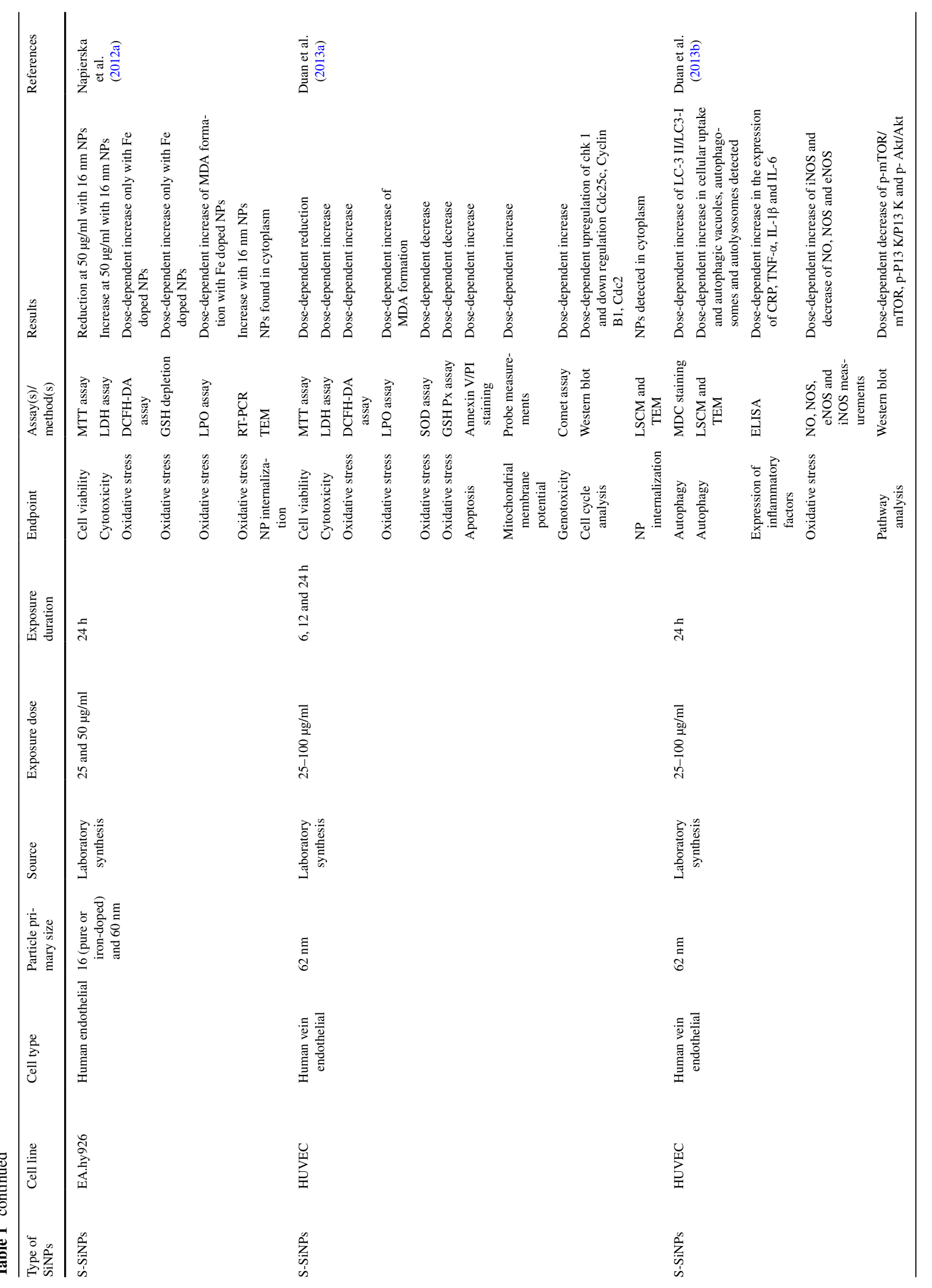




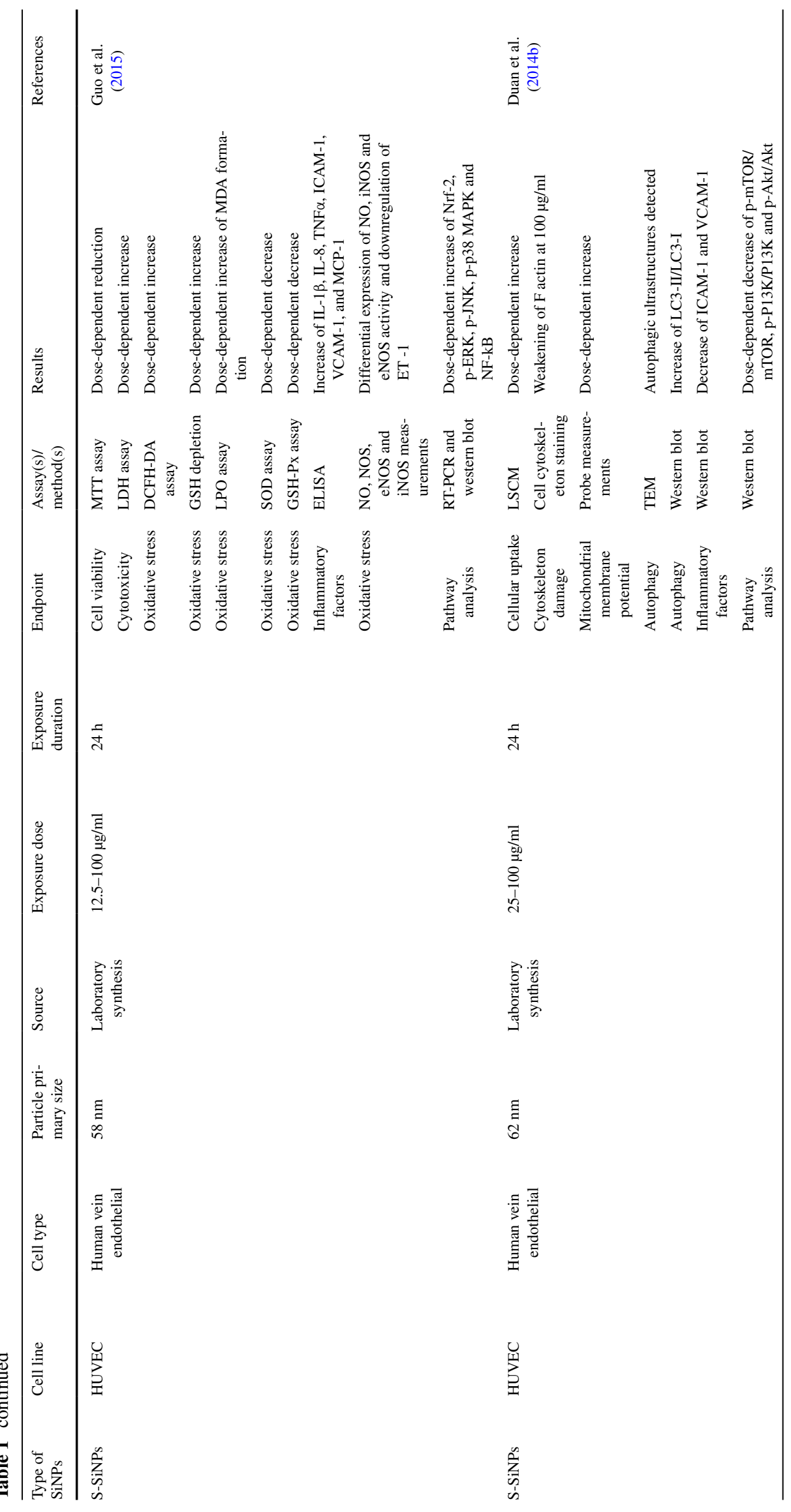




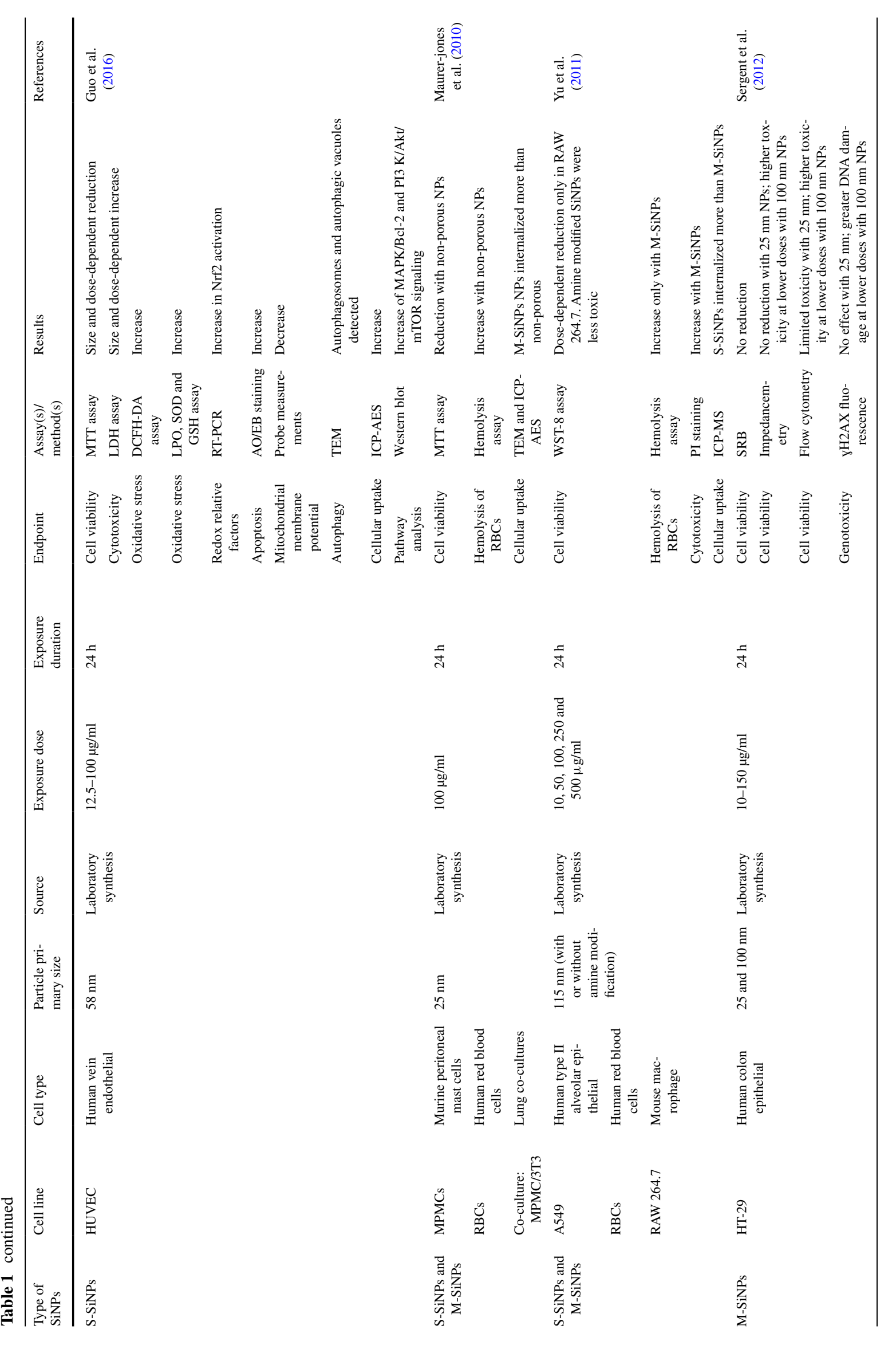




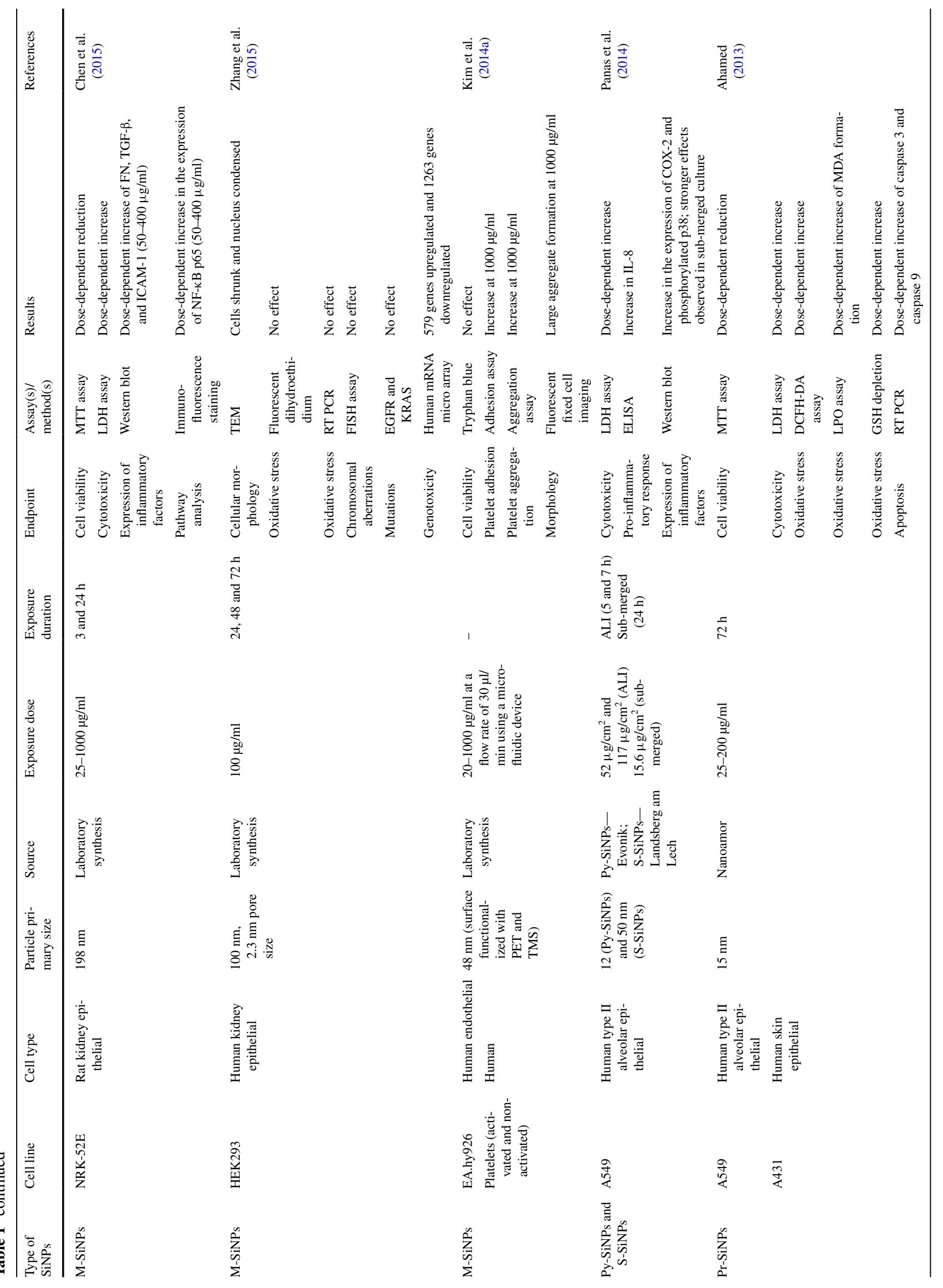




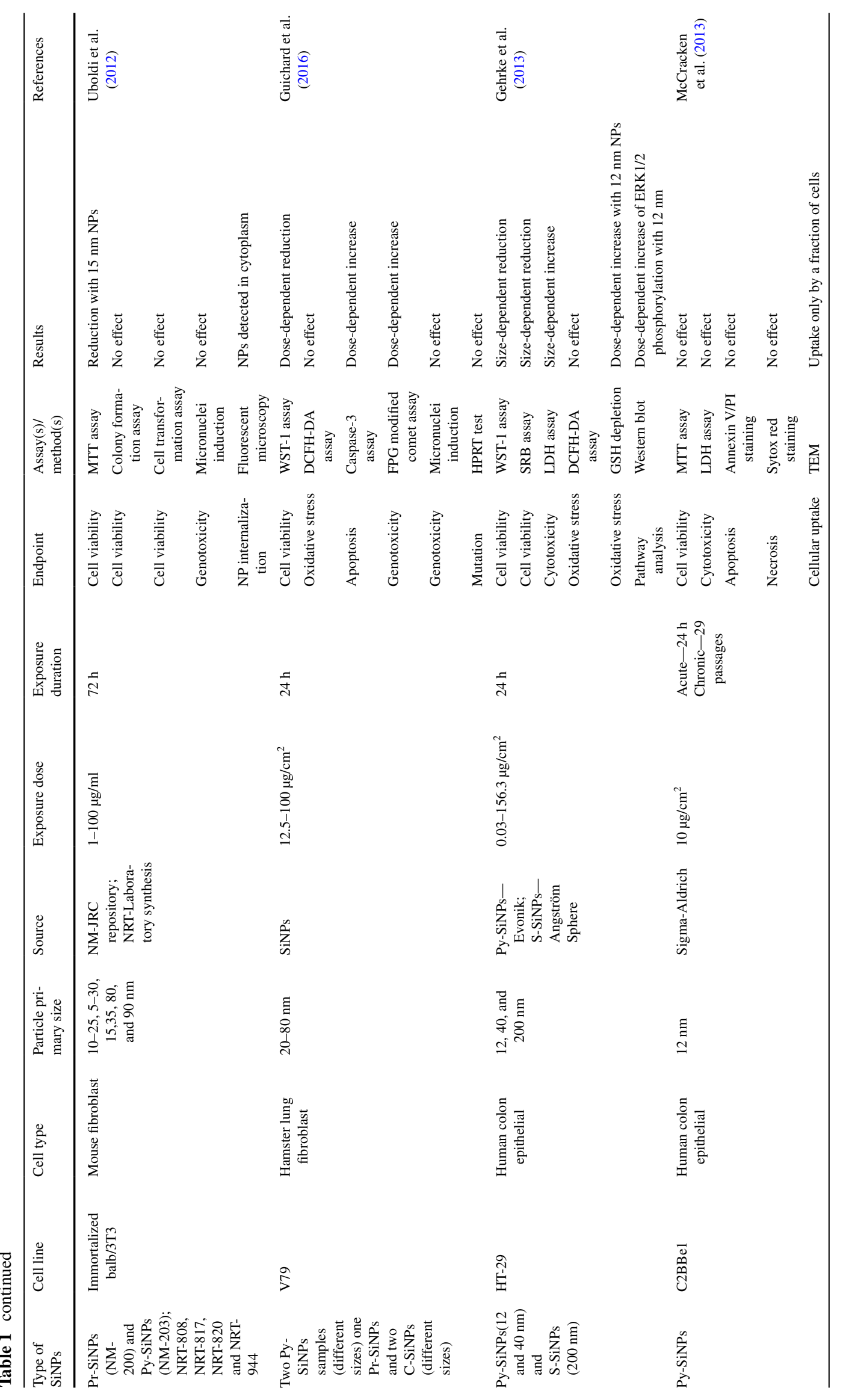




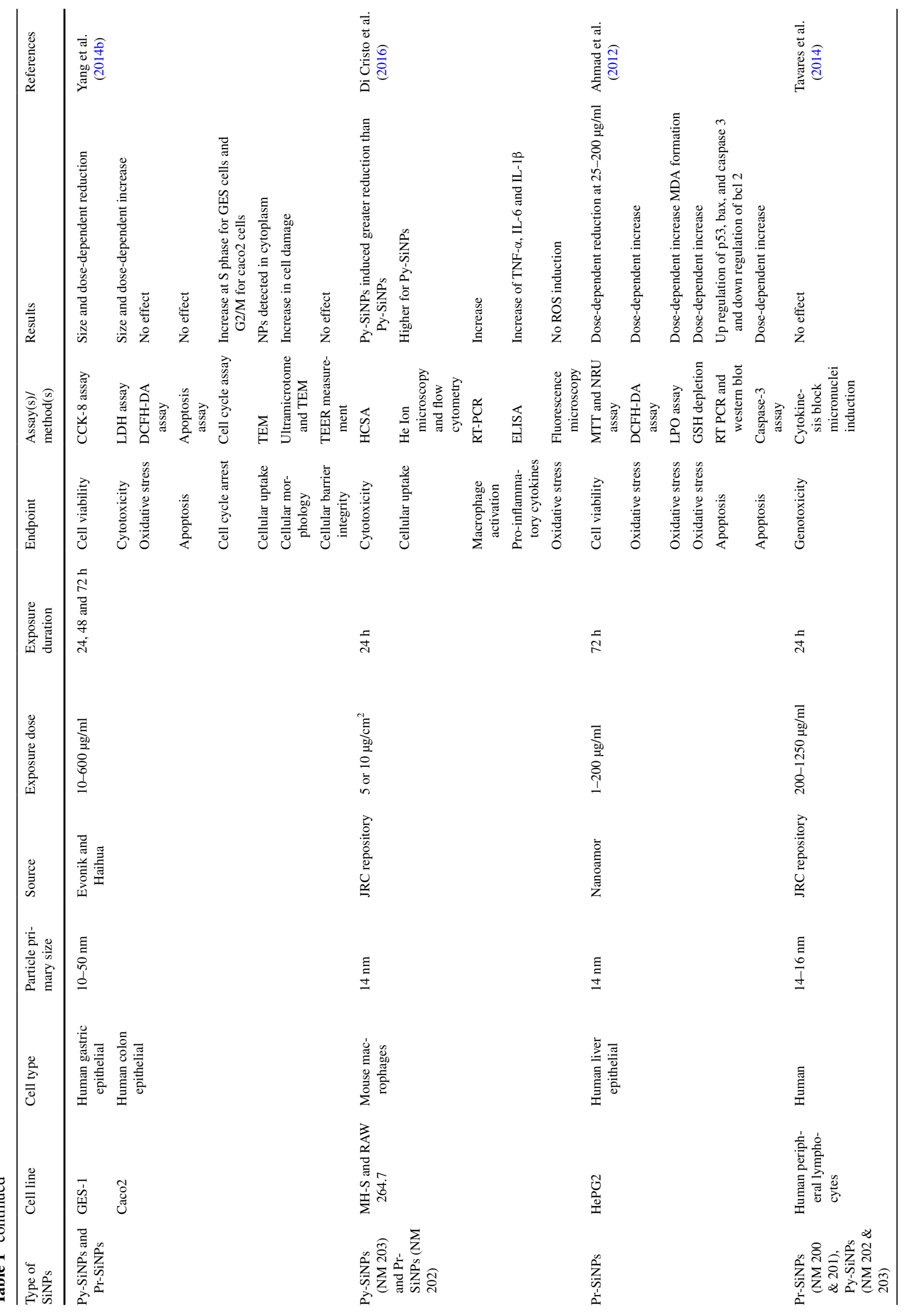




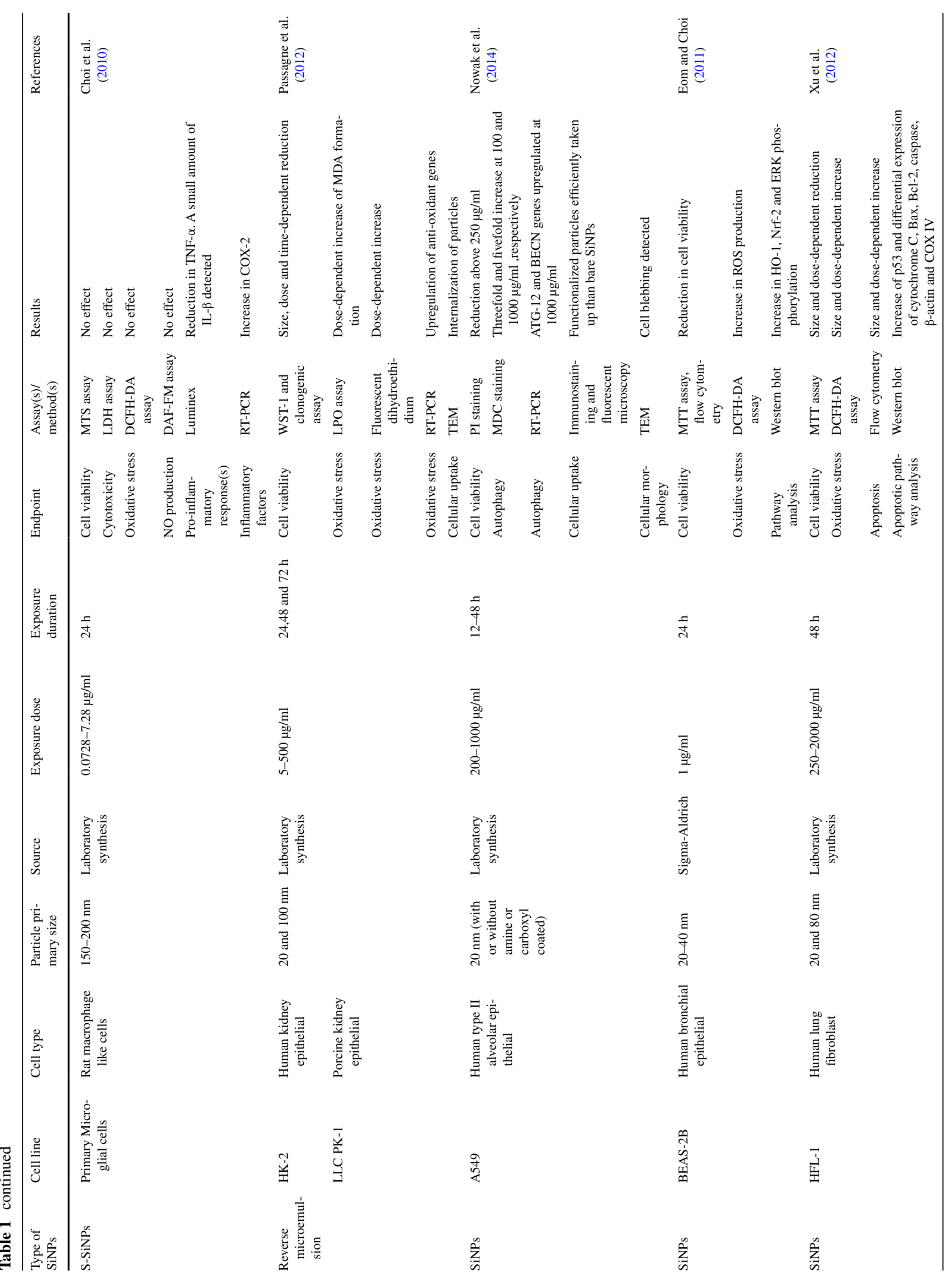




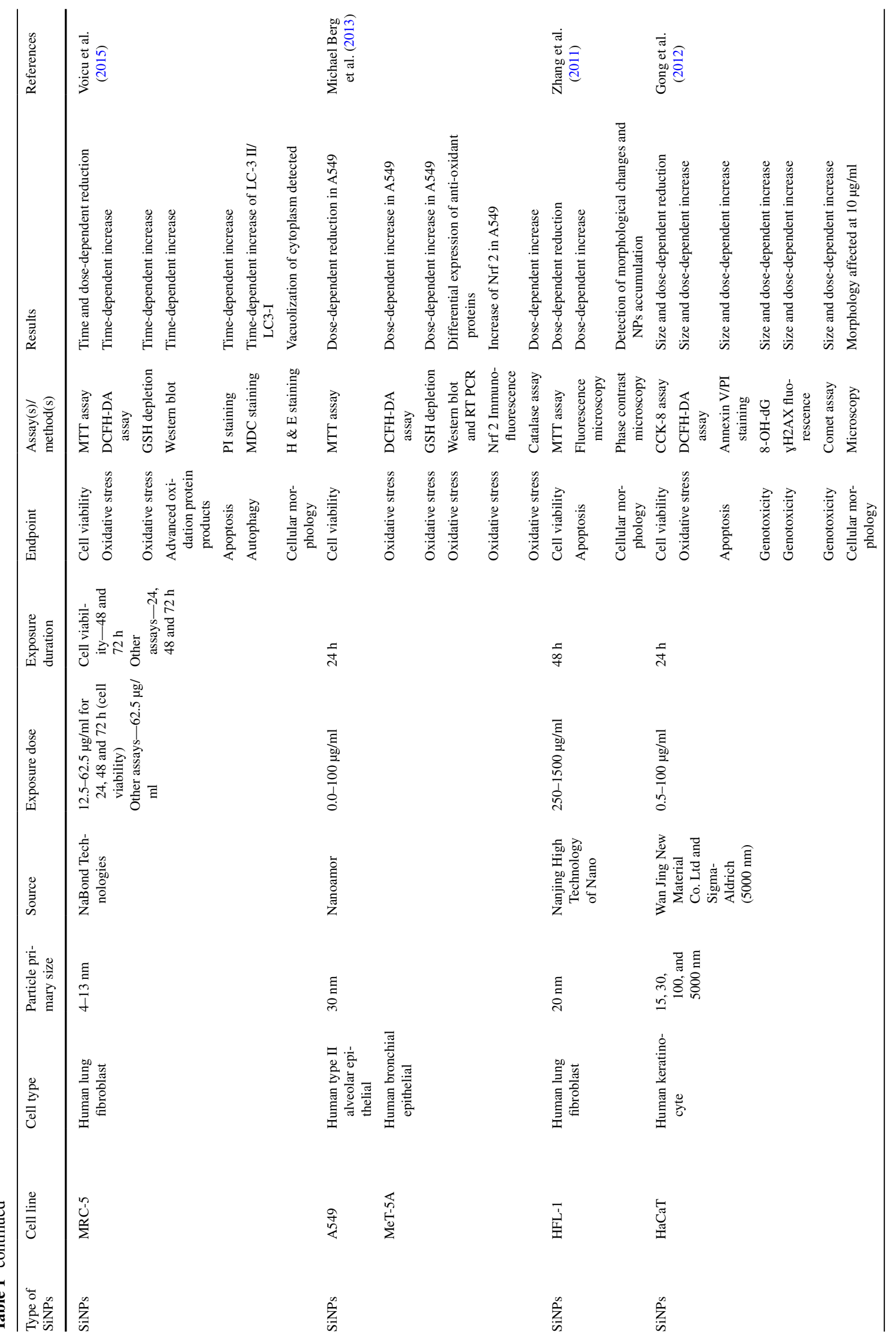




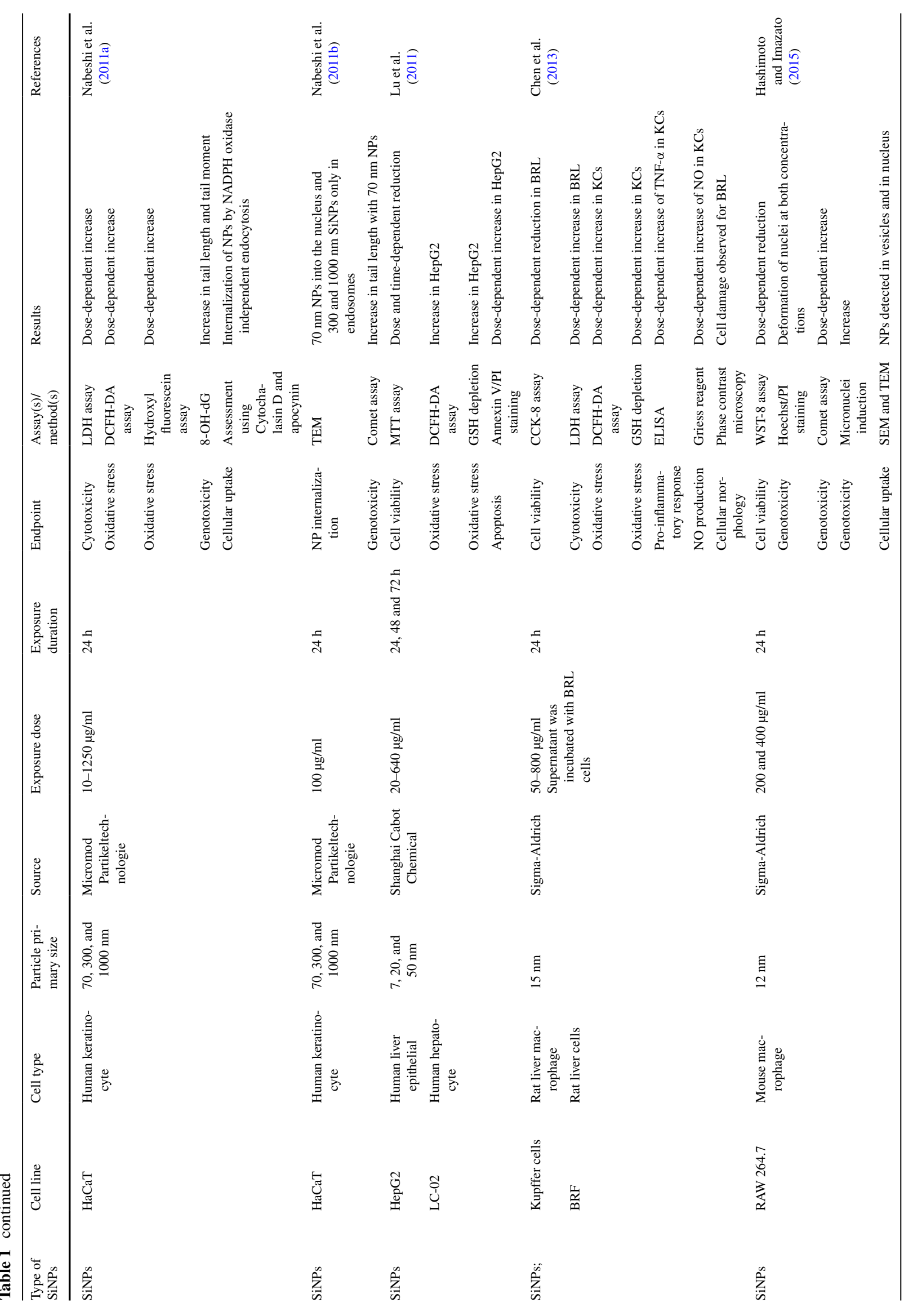




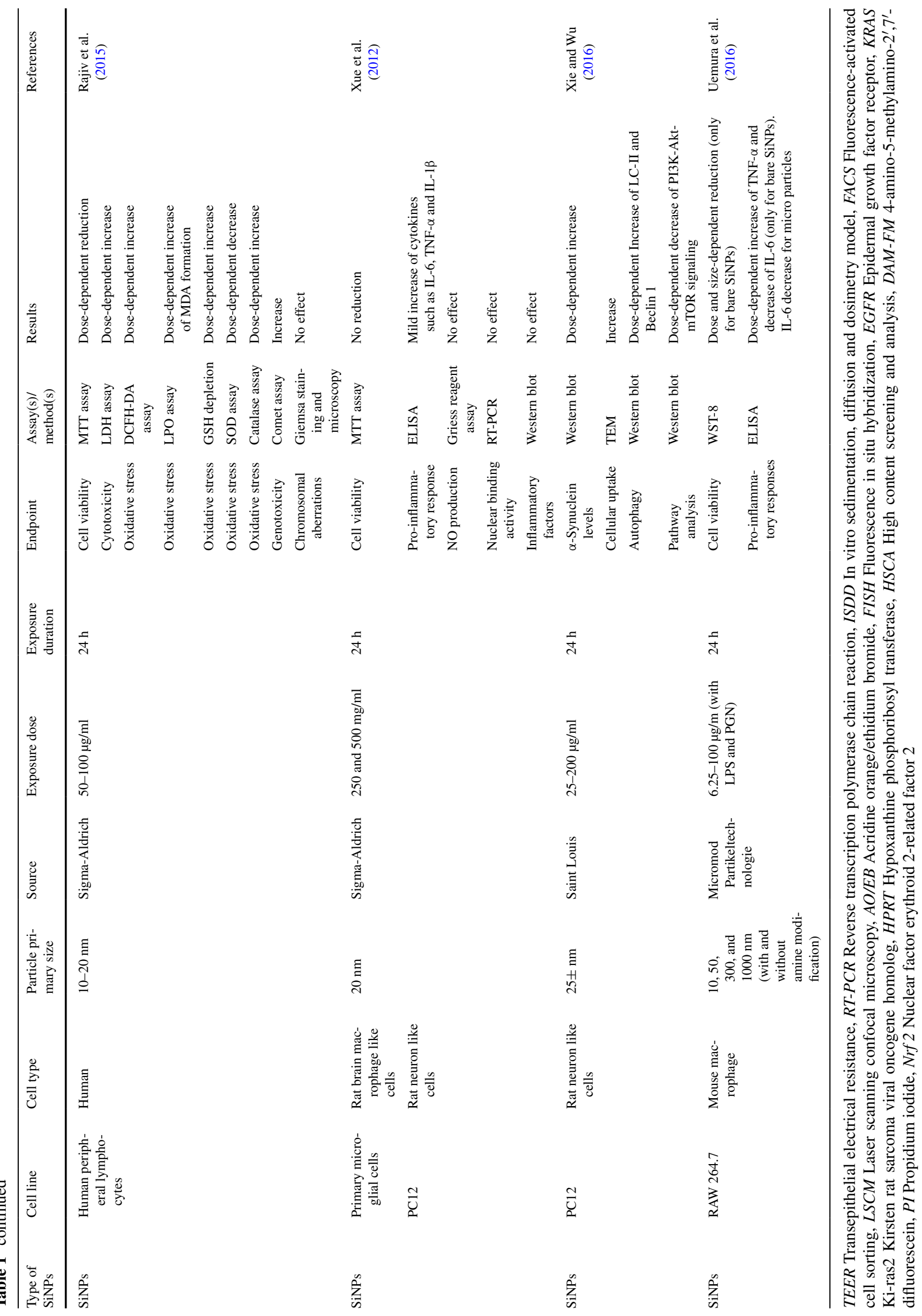




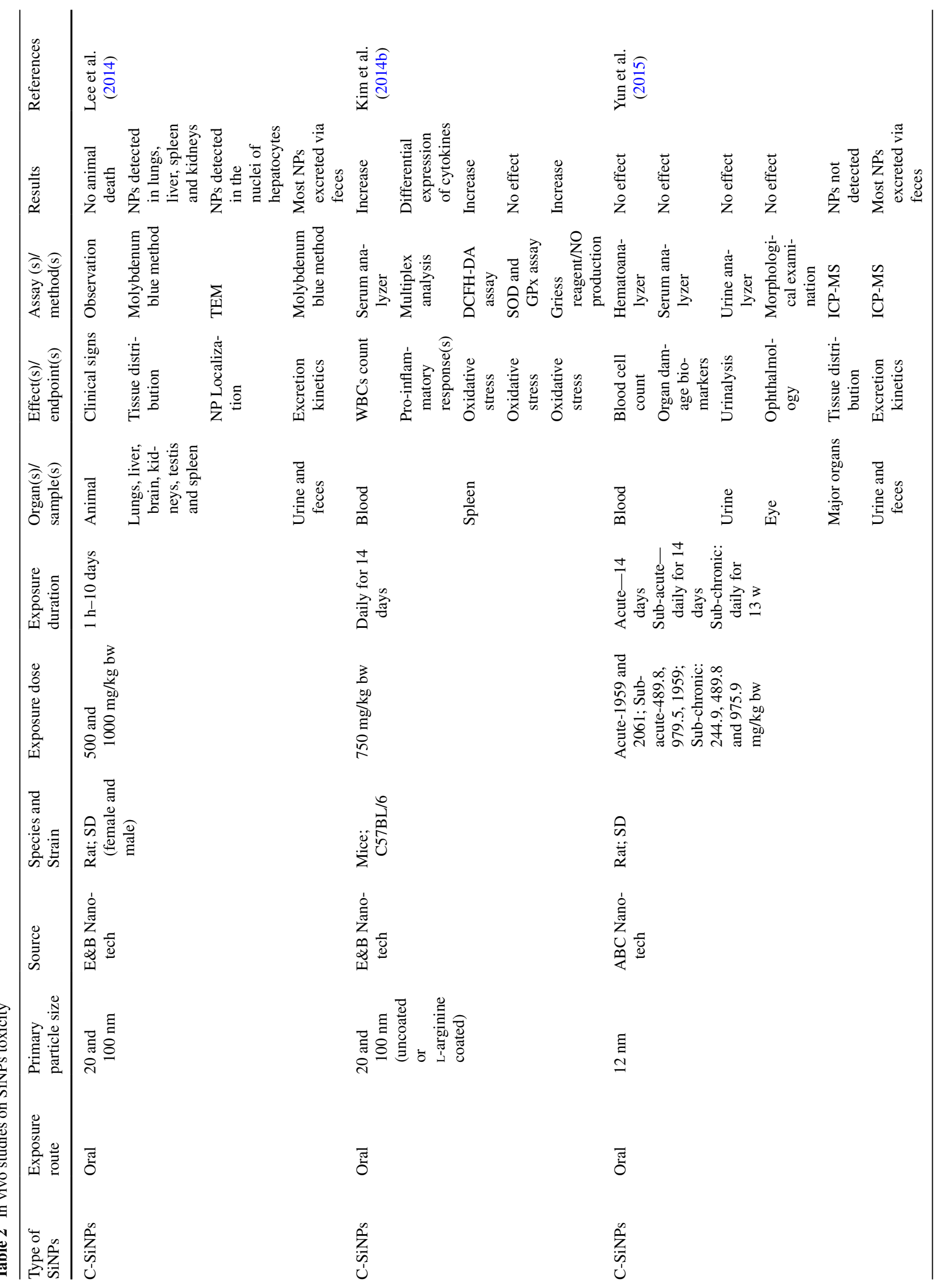




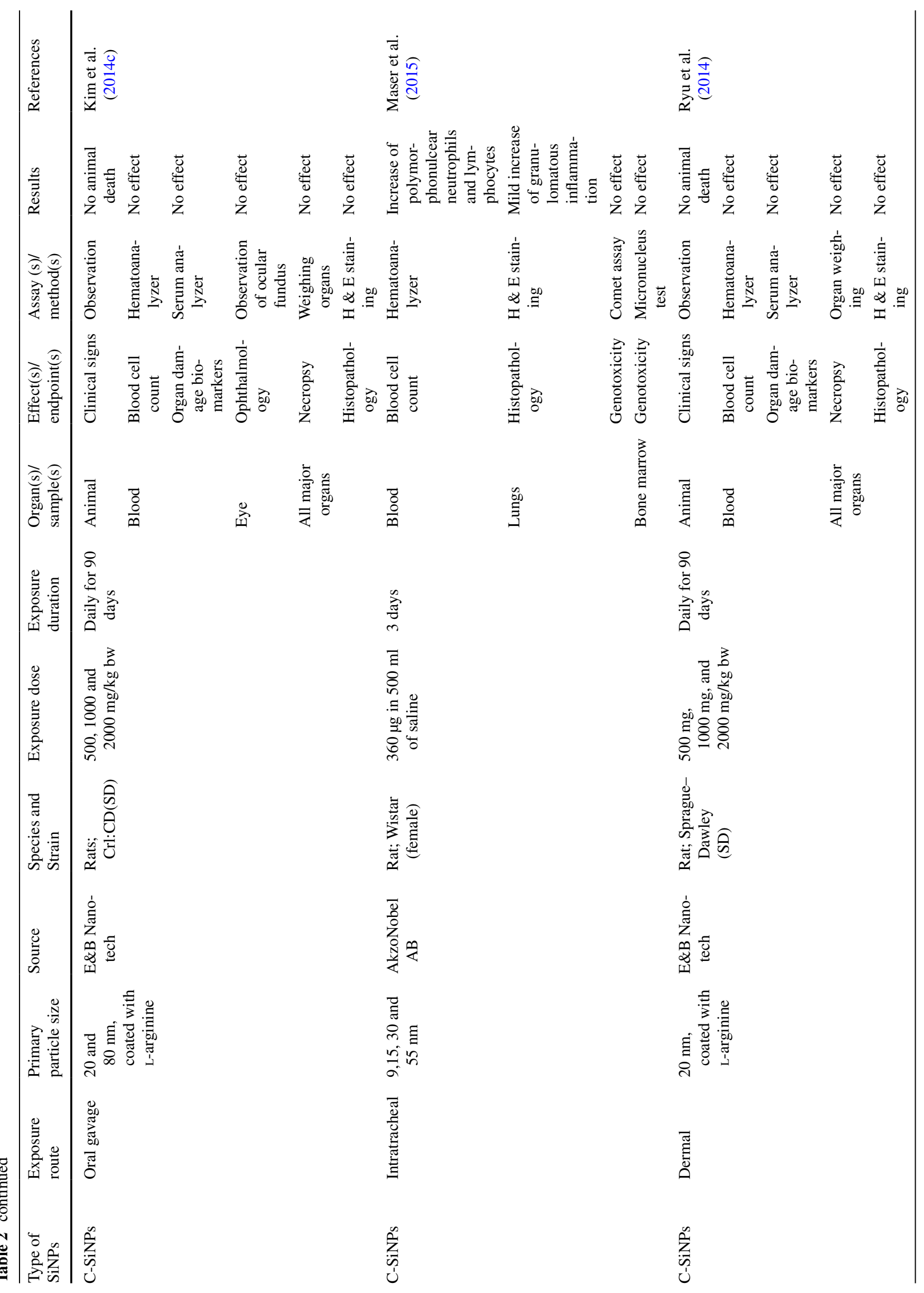




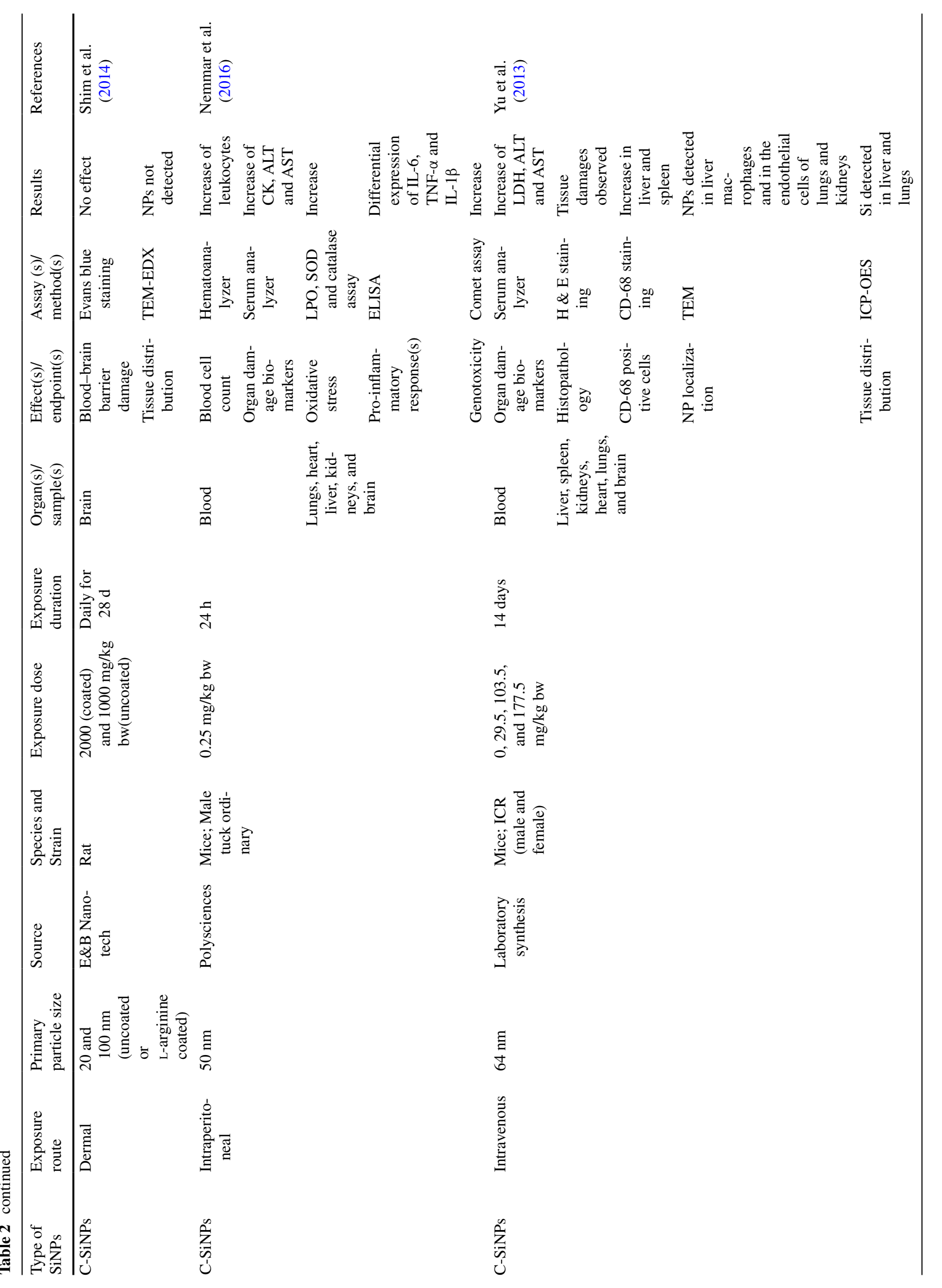


2988

Arch Toxicol (2017) 91:2967-3010

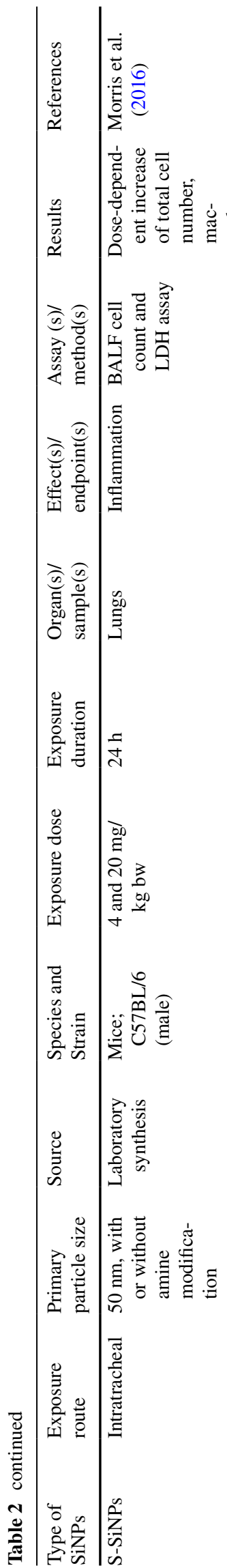

Springer

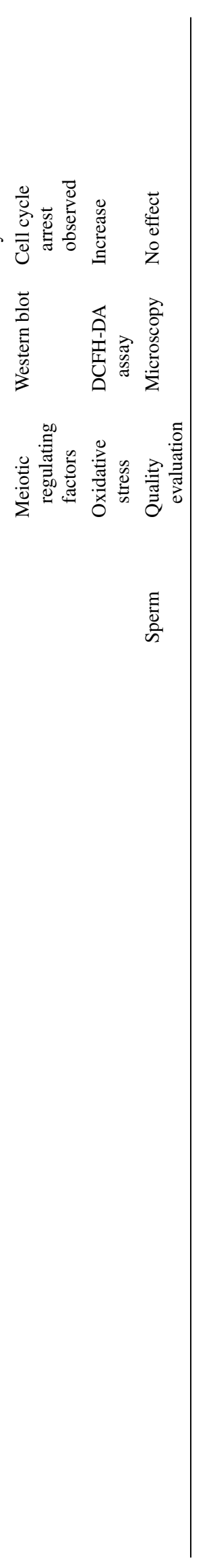

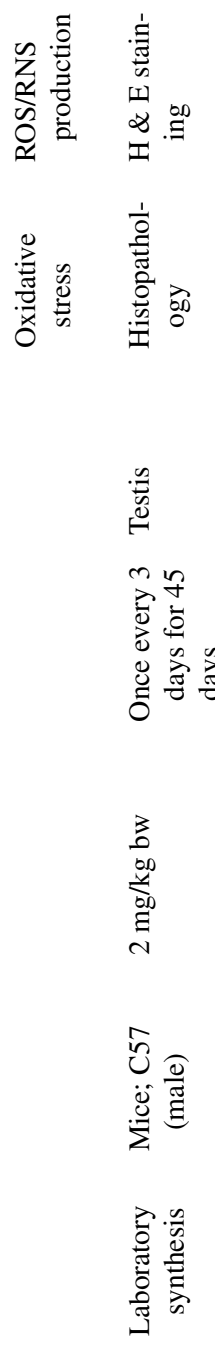

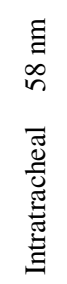




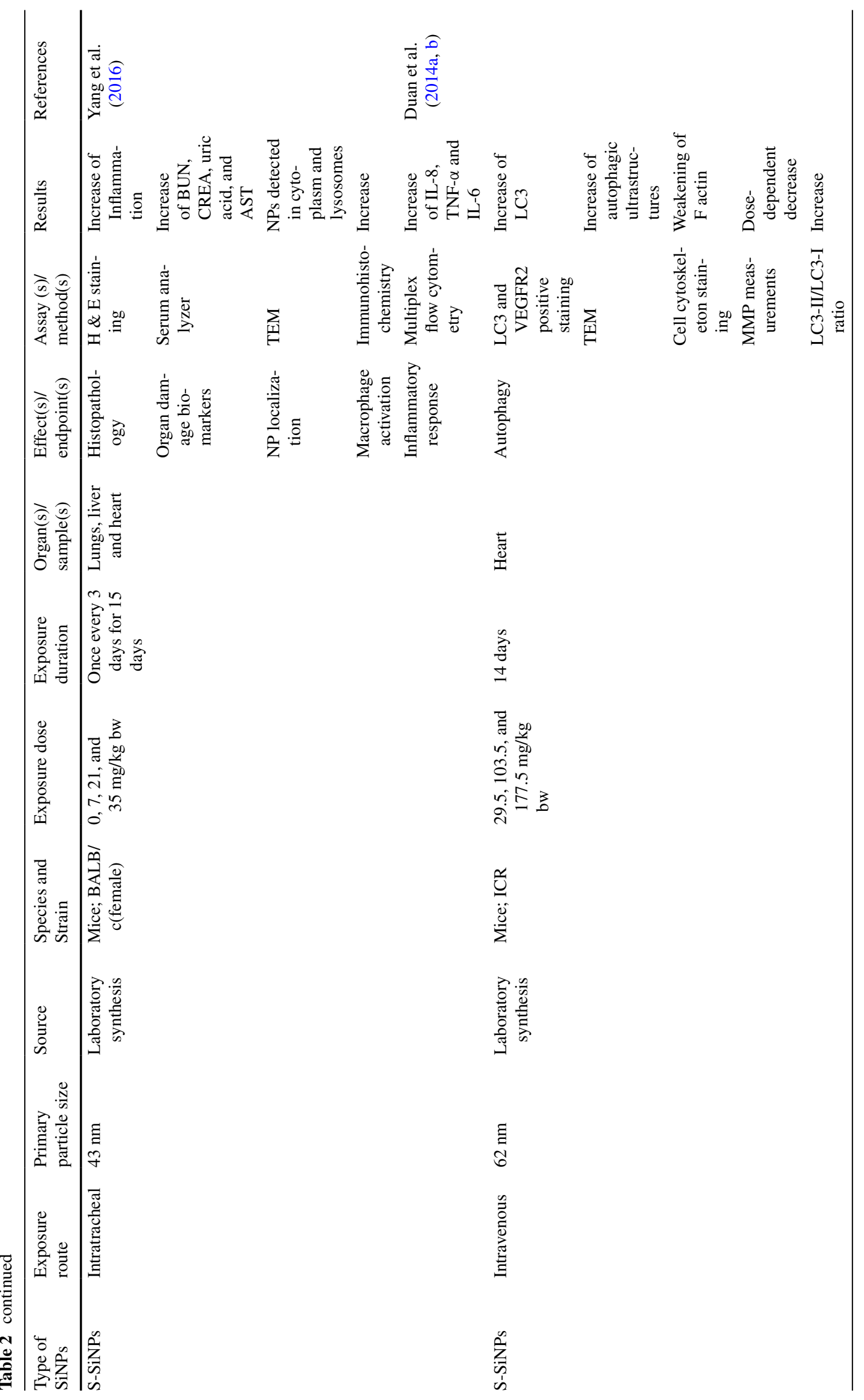




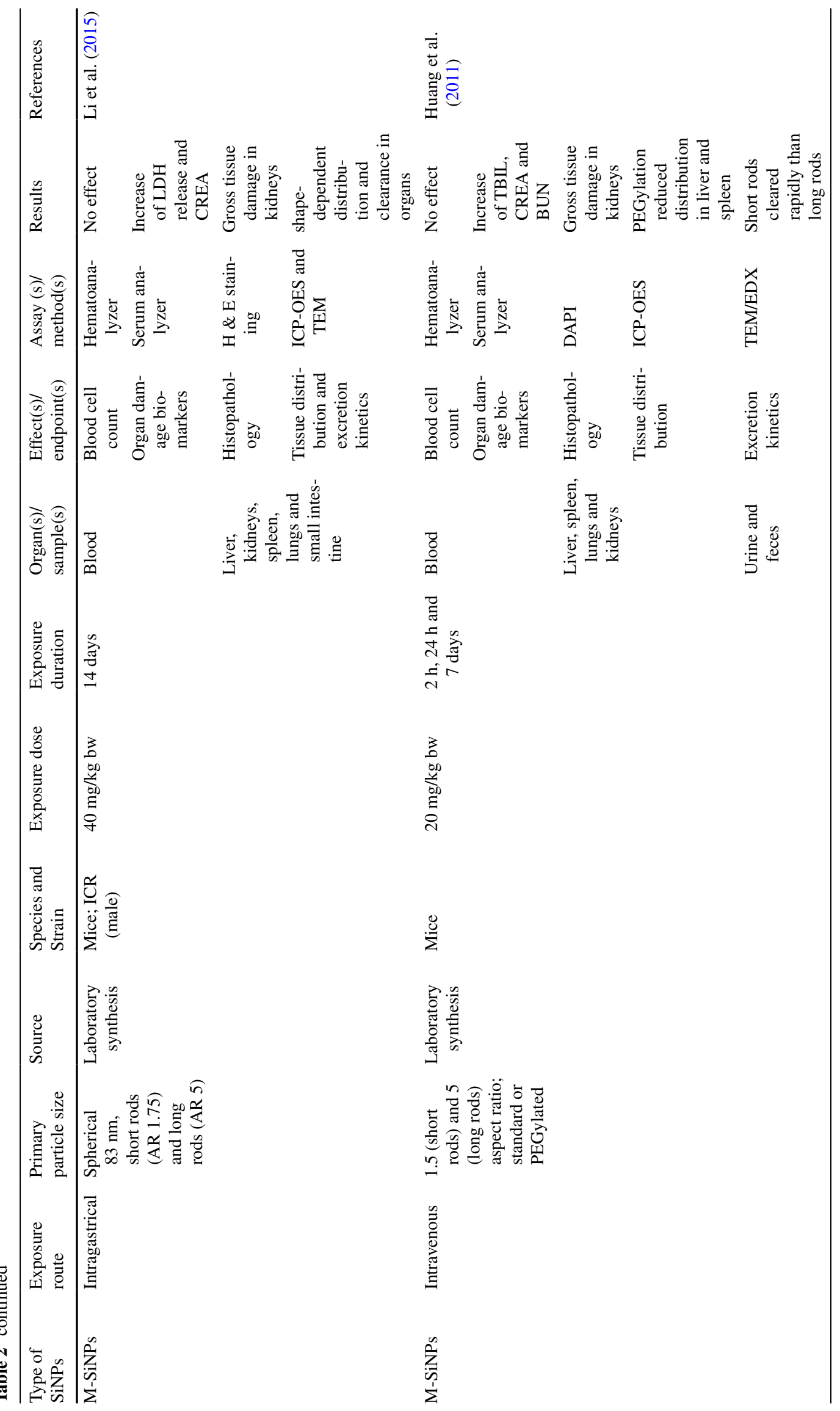




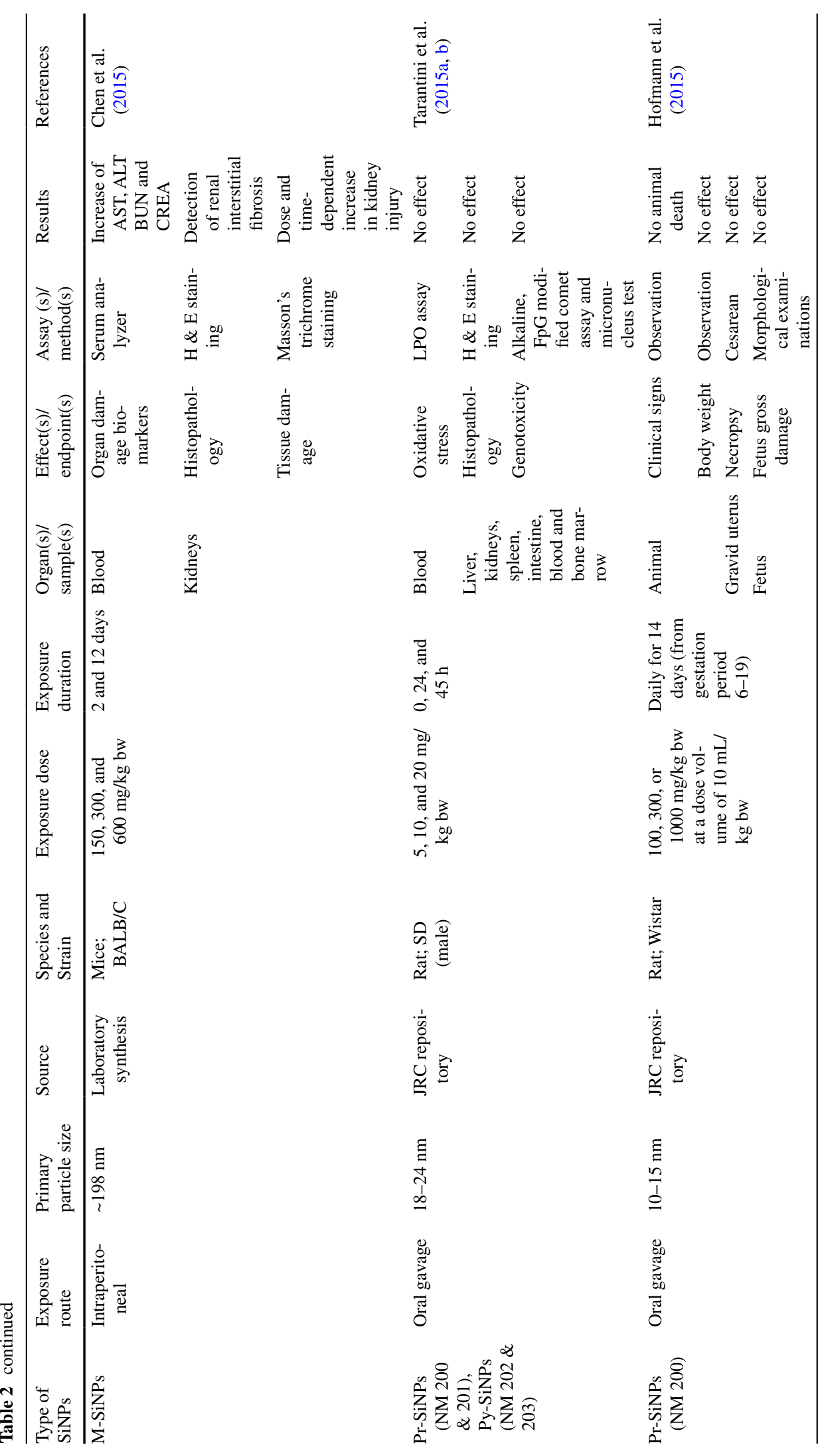




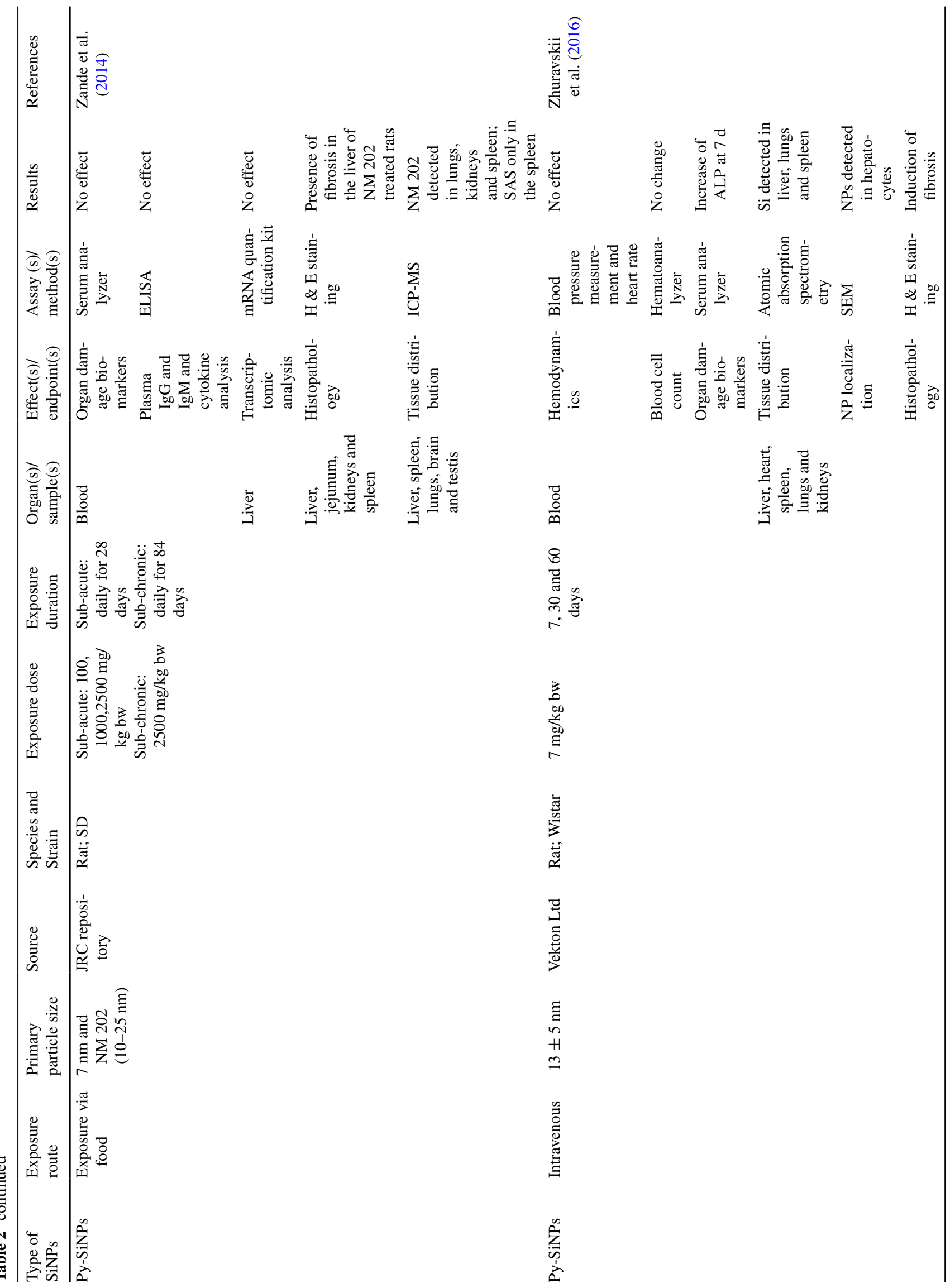




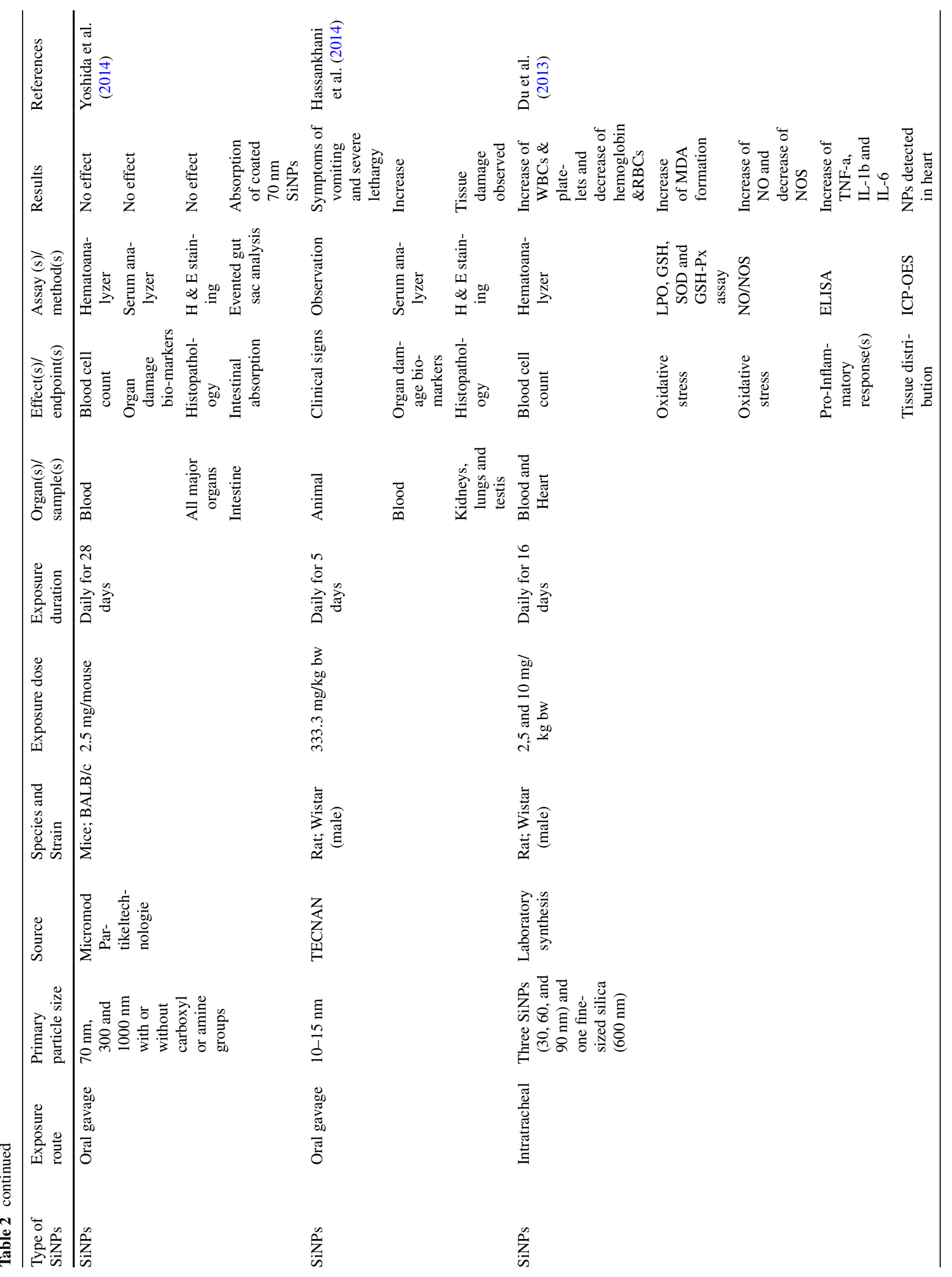




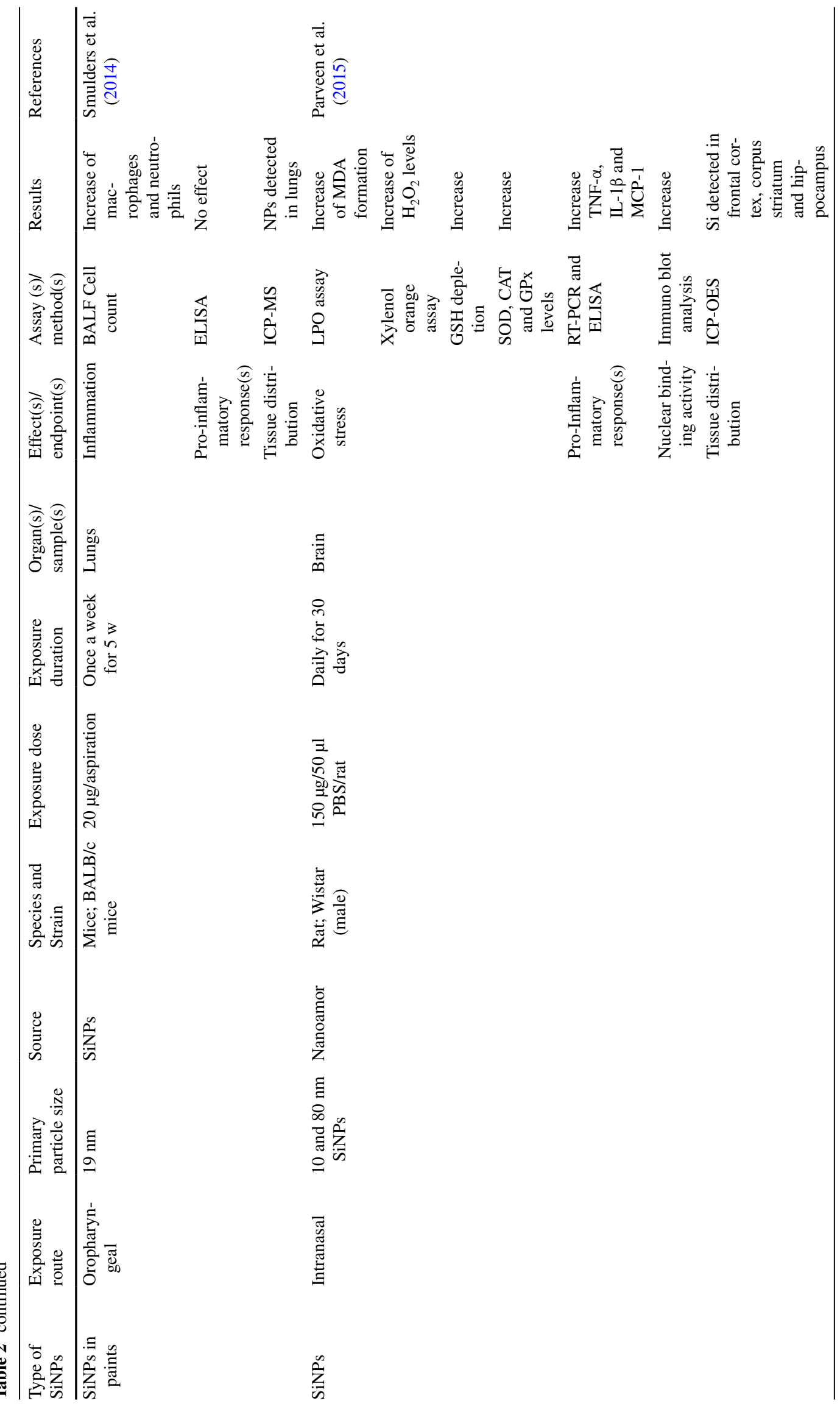




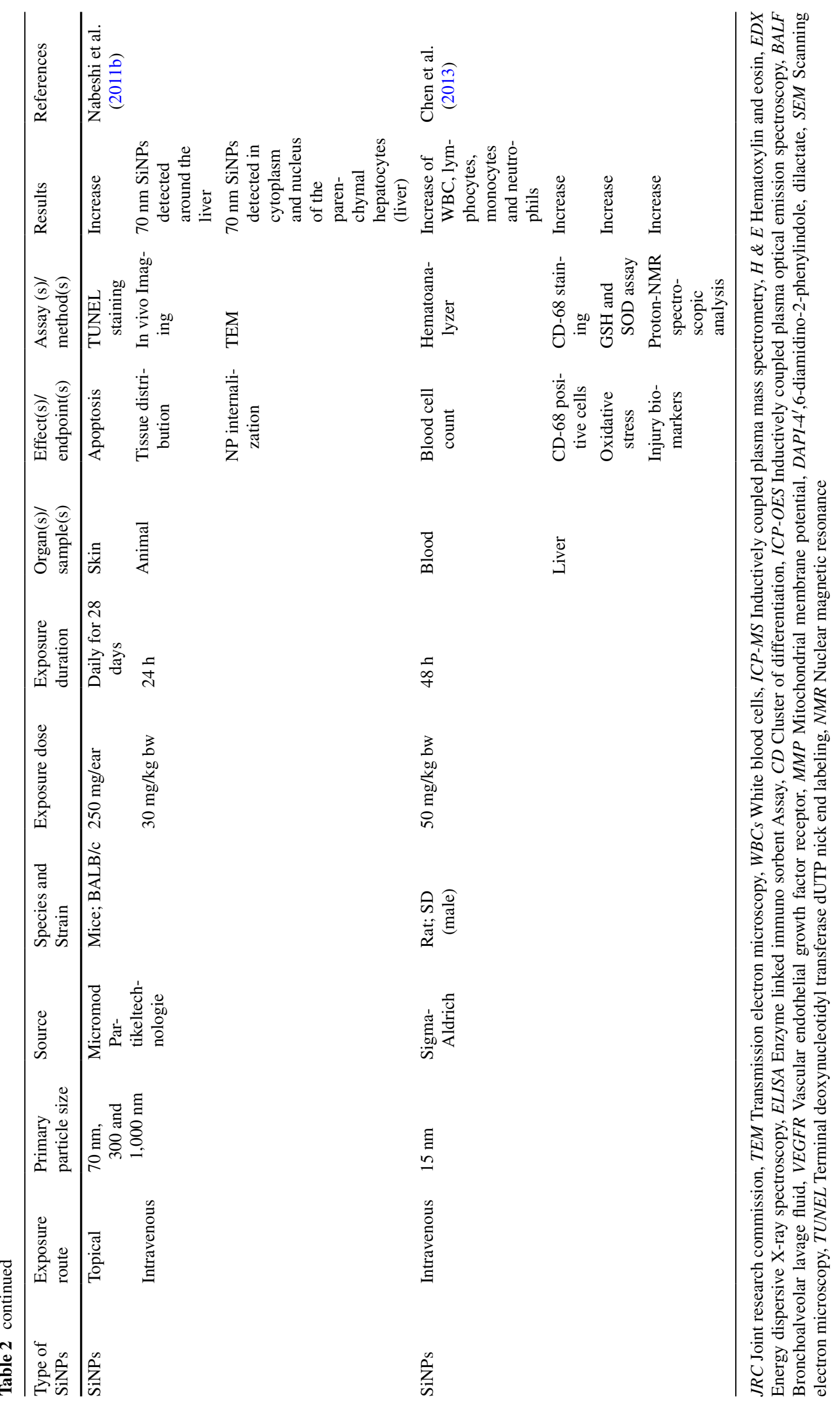


Table 3 Comparison of toxic effects induced by different types of SiNPs (in vitro)

\begin{tabular}{|c|c|c|c|c|c|c|c|}
\hline SiNP type & Cell type & Cytotoxicity & Apoptosis & Genotoxicity & Oxidative stress & Pro-inflammation & References \\
\hline Colloidal & $\mathrm{Caco} 2$ & $\checkmark$ & $\checkmark$ & $\checkmark$ & $\checkmark$ & $\checkmark$ & Tarantini et al. $(2015 \mathrm{a}, \mathrm{b})$ \\
\hline Colloidal & HepG2 & $\checkmark$ & $\checkmark$ & $\checkmark$ & $\checkmark$ & $\mathrm{n} / \mathrm{a}$ & Li et al. (2011) \\
\hline Colloidal & V79 and A549 & $\checkmark$ & $\mathrm{n} / \mathrm{a}$ & $\checkmark$ & $\mathrm{n} / \mathrm{a}$ & $\mathrm{n} / \mathrm{a}$ & Maser et al. (2015) \\
\hline Colloidal & $\mathrm{J} 744.1$ & $\checkmark$ & $\checkmark$ & $\mathrm{n} / \mathrm{a}$ & $\checkmark$ & $\checkmark$ & Lee et al. (2011) \\
\hline Colloidal & PBMC & $\checkmark$ & $\checkmark$ & $\mathrm{n} / \mathrm{a}$ & $\checkmark$ & $\checkmark$ & Mendoza et al. (2014) \\
\hline Stöber & Huvecs & $\checkmark$ & $\checkmark$ & $\checkmark$ & $\checkmark$ & $\checkmark$ & Duan et al. (2013a) \\
\hline Stöber & HepG2 & $\checkmark$ & $\checkmark$ & $\mathrm{n} / \mathrm{a}$ & $\checkmark$ & $\mathrm{n} / \mathrm{a}$ & Sun et al. (2011) \\
\hline Stöber & HepG2 & $\checkmark$ & $\checkmark$ & $\mathrm{n} / \mathrm{a}$ & $\checkmark$ & $\mathrm{n} / \mathrm{a}$ & Wang et al. (2013) \\
\hline Stöber & $\mathrm{HaCaT}$ & $\checkmark$ & $\checkmark$ & $\mathrm{n} / \mathrm{a}$ & $\checkmark$ & $\mathrm{n} / \mathrm{a}$ & Liang et al. (2014) \\
\hline Stöber & EA.hy926 & $\checkmark$ & $\mathrm{n} / \mathrm{a}$ & $\mathrm{n} / \mathrm{a}$ & $\checkmark$ & $\mathrm{n} / \mathrm{a}$ & Napierska et al. (2012a, b) \\
\hline Precipitated & V79 & $\checkmark$ & $\checkmark$ & $x$ & $x$ & $\mathrm{n} / \mathrm{a}$ & Guichard et al. (2016) \\
\hline Precipitated & Mouse fibroblast & $\checkmark$ & $\mathrm{n} / \mathrm{a}$ & $x$ & $\mathrm{n} / \mathrm{a}$ & $\mathrm{n} / \mathrm{a}$ & Uboldi et al. (2012) \\
\hline Precipitated & GES- 1 and caco 2 & $\checkmark$ & $\checkmark$ & $\mathrm{n} / \mathrm{a}$ & $\checkmark$ & $\mathrm{n} / \mathrm{a}$ & Yang et al. $(2014 a, b)$ \\
\hline Precipitated & HepG2 & $\checkmark$ & $\checkmark$ & $\mathrm{n} / \mathrm{a}$ & $\checkmark$ & $\mathrm{n} / \mathrm{a}$ & Ahmad et al. (2012) \\
\hline Precipitated & A549 and A431 & $\checkmark$ & $\checkmark$ & $\mathrm{n} / \mathrm{a}$ & $\checkmark$ & $\mathrm{n} / \mathrm{a}$ & Ahamed (2013) \\
\hline Precipitated & M-HS & $\checkmark$ & $\mathrm{n} / \mathrm{a}$ & $\mathrm{n} / \mathrm{a}$ & $x$ & $\checkmark$ & Di Cristo et al. (2016) \\
\hline Precipitated & RAW.264.7 & $\checkmark$ & $\mathrm{n} / \mathrm{a}$ & $\mathrm{n} / \mathrm{a}$ & $x$ & $\checkmark$ & Di Cristo et al. (2016) \\
\hline Pyrogenic & V79 & $\checkmark$ & $\checkmark$ & $\checkmark$ & $x$ & $\mathrm{n} / \mathrm{a}$ & Guichard et al. (2016) \\
\hline Pyrogenic & GES-1 and caco 2 & $\checkmark$ & $\checkmark$ & $\mathrm{n} / \mathrm{a}$ & $x$ & $\mathrm{n} / \mathrm{a}$ & Yang et al. (2014a, b) \\
\hline Pyrogenic & HT-9 & $\checkmark$ & $\mathrm{n} / \mathrm{a}$ & $\mathrm{n} / \mathrm{a}$ & $x$ & $\mathrm{n} / \mathrm{a}$ & Gehrke et al. (2013) \\
\hline Pyrogenic & RAW.264.7 & $\checkmark$ & $\mathrm{n} / \mathrm{a}$ & $\mathrm{n} / \mathrm{a}$ & $x$ & $\checkmark$ & Di Cristo et al. (2016) \\
\hline Pyrogenic & M-HS & $\checkmark$ & $\mathrm{n} / \mathrm{a}$ & $\mathrm{n} / \mathrm{a}$ & $\checkmark$ & $\checkmark$ & Di Cristo et al. (2016) \\
\hline
\end{tabular}

n/a, not investigated; $\boldsymbol{V}$, positive; $\boldsymbol{X}$, negative

including SiNPs (Manke et al. 2013). Nevertheless, Py- and $\mathrm{S}$-SiNPs caused cytotoxicity without measurable levels of ROS production. It was demonstrated that the disturbance of membrane integrity due to direct cell-membrane interaction might be another possible mechanism of NP cytotoxicity (Fröhlich et al. 2009; Thomassen et al. 2011). However, neither of these studies did substantiate these observations and, therefore, SiNPs cytotoxic effects in the absence of oxidative stress remain poorly understood.

Furthermore, some authors used very high concentrations that may cause "overloading" of cells and modify the nature of NP-cell interactions (Wittmaack 2011). In these cases, it is difficult to evaluate whether the observed effects are physiologically relevant. Although it is challenging, we consider a dose of $384 \mu \mathrm{g} / \mathrm{cm}^{2}$ or higher as irrelevant to human inhalation exposure for amorphous silica, based on the estimation that can be derived from the occupational exposure levels (OELs) (Fig. 2).

\section{Genotoxicity}

In this section, we presented studies on genotoxic effects of SiNPs as it is used as another major endpoint to characterize hazard of NMs. Direct interaction with DNA, oxidative DNA damage, depletion of anti-oxidants, cell cycle arrest, and abnormal expression of genes have been identified as potential mechanisms of NP mediated (geno)toxicity (Donaldson et al. 2010).

\section{DNA damage associated with oxidative stress}

Exposure to SiNPs $(15,30$, and $100 \mathrm{~nm})$ resulted in a size- and dose- $(2.5-10 \mu \mathrm{g} / \mathrm{ml}$ for $24 \mathrm{~h})$ dependent increase in 8-hydroxy-2'-deoxyguanosine levels $(8-\mathrm{OH}-$ $\mathrm{dG})$, phosphorylation of histone on serine-139 ( $\mathrm{\gamma H} 2 \mathrm{AX}$ ), and DNA strand breaks (comet) in human keratinocytes (HaCaT) (Gong et al. 2012). Nabeshi et al. (2011a) also
Fig. 2 In vitro dose estimation from human tolerable levels (OELs)

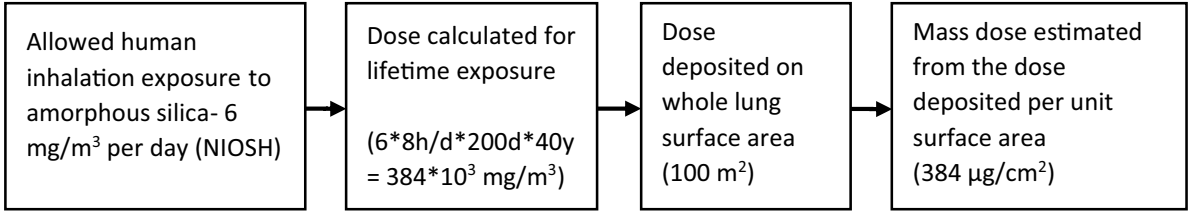


demostrated that exposure to SiNPs $(70 \mathrm{~nm} ; 10-90 \mu \mathrm{g} / \mathrm{ml}$ for $24 \mathrm{~h}$ ) resulted in the increase of oxidative DNA damage (8-OH-dG levels) in HaCaT cells. SiNPs were taken up via actin-mediated endocytosis. Micron-sized particles used in these studies showed no or little effects.

The viability of human Caucasian colon adenocarcinoma (Caco-2) cells dropped to $40 \%$ when exposed to $15 \mathrm{~nm} \mathrm{C}$-SiNPs $(64 \mu \mathrm{g} / \mathrm{ml}$ for $24 \mathrm{~h})$, and, at this same concentration, nearly a threefold increase in micronuclei formation, fivefold increase in histone phosphorylation $(\mathrm{\gamma H} 2 \mathrm{AX})$, and a significant increase in DCF fluorescence were observed. The particles were localized within lysosomes and endocytic compartments, but not in the nucleus. $55 \mathrm{~nm} \mathrm{C}$-SiNPs did not induce any of these effects at the same concentration (Tarantini et al. 2015b).

A non-significant increase in \% tail DNA (comet assay) and no chromosomal aberrations were induced by $17 \mathrm{~nm}$ SiNPs in human peripheral lymphocytes treated with $100 \mu \mathrm{g} / \mathrm{ml}$, while a dose-dependent $(50-100 \mu \mathrm{g} / \mathrm{ml}$ for $24 \mathrm{~h}$ ) ROS production (DCFH-DA) and GSH depletion were observed (Rajiv et al. 2015).

\section{Cell cycle arrest associated with oxidative stress}

S-SiNPs $(62 \mathrm{~nm})$ induced increase in DCF fluorescence and decrease in superoxide dismutase (SOD) and glutathione peroxidase (GSH-Px) in HUVECs in a dosedependent manner $(25-100 \mu \mathrm{g} / \mathrm{ml}$ for $24 \mathrm{~h})$. Oxidative stress was linked to cell cycle arrest at G2/M checkpoint (upregulation of chk 1 and downregulation of Cdc25c, Cyclin B1, and Cdc2) and increase in apoptosis (Duan et al. 2013a). In the study by $\mathrm{Li}$ et al. (2011), a sizedependent $(19,43$, and $68 \mathrm{~nm})$ increase in oxidative stress (DCF fluorescence) and cell cycle arrest in S and G2/M was observed in HepG2 cells exposed to $100 \mu \mathrm{g} / \mathrm{ml}$ of C-SiNPs. Cell cycle arrest in G2/M phase along with the increase in ROS was also noticed in human hepatic cell line (LC-02) treated with S-SiNPs $(50 \mathrm{~nm})$ in a dosedependent manner (50-200 $\mu \mathrm{g} / \mathrm{ml}$ for $24 \mathrm{~h}$ ) (Wang et al. 2013).

\section{DNA damage not associated with oxidative stress}

Genotoxicity of Py-SNP (20 and 25-70 nm), Pr-SNP (20 nm), and C-SNP (15 and 40-80 nm) SiNPs were studied in Chinese hamster lung fibroblasts. Py-SiNPs $(20 \mathrm{~nm})$ induced a significant increase in DNA strand breaks at $66 \mu \mathrm{g} / \mathrm{ml}(24 \mathrm{~h})$, while C-SiNPs $(15 \mathrm{~nm})$ showed a similar effect only at $252 \mu \mathrm{g} / \mathrm{ml}$. Neither of these SiNPs did induce ROS. SiNPs in the size range $25-80 \mathrm{~nm}$ exerted no or little genotoxicity (Guichard et al. 2016).
Genotoxicity reports without the assessment of oxidative stress

M-SiNPs $(100 \mathrm{~nm})$ induced a significant increase in phosphorylated-yH2AX-foci in HT-29 cells treated with a dose of $10 \mu \mathrm{g} / \mathrm{ml}$ for $24 \mathrm{~h}$ (Sergent et al. 2012). In the human embryonic kidney cell line (HEK293), 579 genes were upregulated and 1263 genes were downregulated after $24 \mathrm{~h}$ of exposure $(100 \mu \mathrm{g} / \mathrm{ml})$ to $100 \mathrm{~nm} \mathrm{M-SiNPs}$ (Zhang et al. 2015). In another study, 15-nm C-SiNPs induced a significant increase in DNA strand breaks (comet assay) in chinese hamster cells (V79) and A549 cells at $100 \mu \mathrm{g} /$ $\mathrm{ml}(24 \mathrm{~h})$, but, for $55 \mathrm{~nm}$, this effect was observed only in A549 cells (Maser et al. 2015). A significant increase in DNA tail length (comet assay) was observed in HaCaT cells treated with $30 \mu \mathrm{g} / \mathrm{ml}(24 \mathrm{~h}$ ) of $70 \mathrm{~nm}$ SiNPs (Nabeshi et al. 2011b).

Exposure to C-SiNPs $(\sim 7 \mathrm{~nm})$ resulted in positive genotoxic effects (Lymphoma assay) in mouse lymphoma cells treated with 100 and $150 \mu \mathrm{g} / \mathrm{ml}$ for $4 \mathrm{~h}$ (Demir and Castranova 2016). SiNPs (12 nm) induced DNA strand breaks in RAW 264.7 at 200 and $400 \mu \mathrm{g} / \mathrm{ml}$, but the induction of micronuclei was noticed only at $400 \mu \mathrm{g} / \mathrm{ml}$. The particles were internalized in vesicles and in the nucleus (Hashimoto and Imazato 2015).

At any tested concentrations $(1-100 \mu \mathrm{g} / \mathrm{ml}$ for $72 \mathrm{~h}$ ), SiNPs $(10-25,5-30,35,15,80$, and $90 \mathrm{~nm})$ neither induced cytotoxicity nor micronuclei in immortalized Balb/3T3 fibroblasts (Uboldi et al. 2012). In another study, Pr-SiNPs (NM-200 and NM-201) and Py-SiNPs (NM-202 and NM-203) with primary size between 14.5 and $16 \mathrm{~nm}$ did not induce any micronuclei (cytokinesis block micronucleus assay) in human peripheral lymphocytes exposed to different concentrations $(200-1250 \mu \mathrm{g} / \mathrm{ml})$ over $24 \mathrm{~h}$ (Tavares et al. 2014). It is also worthy to note that, in the latter study, the positive control used did not differ from control conditions.

\section{Conclusion: genotoxicity}

C-SiNPs and S-SiNPs induced genotoxicity in human tumor cell lines (lung, kidney, skin, and gastro-intestinal systems) and the amplitude of the effect negatively correlated with the size of the NPs. DNA strand breaks were observed at low concentrations $(2.5-10 \mu \mathrm{g} / \mathrm{ml})$, particularly in skin-derived cell lines. The genotoxic effects of $\mathrm{C}$ - and S-SiNPs were mainly associated with the induction of oxidative stress, while such information is very limited for other types (Py- and Pr-SiNPs). One study indicated that Py-SiNPs induce DNA damage without the generation of ROS, suggesting that other mechanisms such as direct DNA damage might be involved (Magdolenova et al. 2014). However, it is very difficult to judge whether 
such genotoxic effect is direct or indirect, since the cellular uptake and subcellular localization of SiNPs are not often reported. Furthermore, several factors such as SiNP properties, cell type, and exposure scenarios (such as concentrations, assays, and endpoints) may influence the outcomes (Magdolenova et al. 2014), making the comparison difficult between studies and indicating an urgent need for the standardization of genotoxicity studies.

\section{Immunotoxicity}

NPs entering the body will most probably interact with immune cells, as they are the first line of defence in human body. In this section, we presented the immune responses induced by SiNPs in different cell lines.

\section{Immunotoxicity associated with oxidative stress}

Hara et al. (2014) exposed THP-1-derived macrophages to $100 \mu \mathrm{g} / \mathrm{ml}$ of SiNPs $(30 \mathrm{~nm})$ for $6 \mathrm{~h}$ and found a significant increase in interleukin-1-beta (IL-1 $\beta$ ), ROS production, and SiNP uptake via phagocytosis. In the study of Choi et al. (2010), larger sized SiNPs (150-200 nm) were effectively phagocytosed by primary rat microglial cells after $24 \mathrm{~h}$ of exposure to different concentrations $(0.0728-7.28 \mu \mathrm{g} / \mathrm{ml})$. A significant increase in ROS, reactive nitrogen species (RNS) and IL-1 $\beta$ was detected at all concentrations.

\section{Immunotoxicity not associated with oxidative stress}

At 10 and $20 \mu \mathrm{g} / \mathrm{ml}$, Di Cristo et al. (2016) found that Py-SiNPs $(\sim 14 \mathrm{~nm})$ induced a stronger increase of tumor necrosis factor-alpha (TNF- $\alpha$ ), interleukin(IL)-6, and IL-1 $\beta$ in RAW.264.7 macrophages compared to similar sized PrSiNPs; Notably, no SiNPs induced ROS in RAW.264.7 macrophages.

\section{Immunotoxicity reports without the assessment of oxidative} stress

A significant increase in TNF- $\alpha$, IL-6, and IL- $1 \alpha$, mitogen activated protein kinases (MAPKs), and nuclear factor $(\mathrm{NF})-\kappa \mathrm{B}$ were observed only for C-SiNPs $(100 \mathrm{~nm})$ in J774A.1 macrophages exposed to $100 \mu \mathrm{g} / \mathrm{ml}$ of same sized $(100 \mathrm{~nm}) \mathrm{C}-\mathrm{SiNPs}$ or M-SiNPs (Lee et al. 2011).

Uemura et al. (2016) showed that SiNPs (10 and $50 \mathrm{~nm}$ ) caused dose-dependent $(6.25-100 \mu \mathrm{g} / \mathrm{ml})$ increase in the production of TNF- $\alpha$ and decrease of IL-6 in RAW.264.7 macrophages, while their amine surface-modified counterparts did not. Furthermore, 300 and 1000 nm micronsized particles (both bare and amine modified) also showed a dose-dependent decrease of IL-6. Notably, the effects were stronger for $50 \mathrm{~nm}$ compared to other particles. The same cell line was utilized by Yu et al. (2011) to investigate phagocytosis using inductively coupled plasma mass spectroscopy (ICP-MS), and they found that S-SiNPs $(25 \mathrm{~nm})$ were phagocytosed at least ten times more than M-SiNPs of same size and high aspect ratio SiNPs (AR 2, 4, and 8). In the study by Napierska et al. (2012b), THP-1 cells dosed with $5 \mu \mathrm{g} / \mathrm{cm}^{2}$ S-SiNPs $(2 \mathrm{~nm})$ showed a significant increase of IL- 8 , TNF- $\alpha$, and macrophage inflammatory protein (MIP)-1 $\alpha$, while only a non-significant increase in MIP-1 $\alpha$ expression was observed for 16 and $104 \mathrm{~nm}$ S-SiNPs.

\section{Conclusion: immunotoxicity}

The main cells used to study immune responses to SiNPs were 'innate' cells such as monocytes and macrophages. Therefore, the identified in vitro studies only address a very limited part of the immune system, essentially pro-inflammatory responses and potential phagocytosis. Furthermore, the data on immune responses and oxidative stress are very limited and, therefore, no firm conclusions can be made. SiNPs, not only induced stronger pro-inflammatory responses compared to sub-micron and micron sized particles but also size-specific effects within the nano-range in immune cells are observed. Besides size, shape and porosity seem to influence the phagocytosis of SiNPs.

\section{Autophagy}

Recently, a growing body of evidence identified autophagy as a cellular defence mechanism against NP toxicity, since it plays a key role in removing misfolded proteins and clearing damaged organelles (Glick et al. 2010). Hence, we present here studies that show induction of autophagy upon exposure to SiNPs.

\section{Autophagy associated with oxidative stress}

The same S-SiNPs $(62 \mathrm{~nm})$ were used in three studies to investigate the induction of autophagy. Along with the dose-dependent $(25-100 \mu \mathrm{g} / \mathrm{ml})$ increase in ROS production, increase in autophagy bio-marker-microtubule-associated protein 1A/1B-light chain 3 (LC3) and monodansylcadaverine (MDC) labelled autophagic vacuoles were detected in HepG2 cells treated with $62 \mathrm{~nm} \mathrm{S-SiNPs.}$ In addition, transmission electron microscopy (TEM) images revealed that autophagosomes and autolysosomes induced in the presence of SiNPs (Yu et al. 2014). The same S-SiNPs $(62 \mathrm{~nm})$ induced increase of LC3-II/LC3-I ratio and decrease of p-mTOR/mTOR, p-P13 K/P13 K and p-Akt/Akt in HUVEC cells in a dose-dependent (25$100 \mu \mathrm{g} / \mathrm{ml}$ ) manner (Duan et al. 2013b, 2014a, b). The results of Guo et al. (2016) also suggest that $50 \mu \mathrm{g} / \mathrm{ml}$ 
of S-SiNPs $(58 \mathrm{~nm})$ could induce autophagy via MAPK/ Bcl-2 and PI3K/Akt/mTOR signaling in HUVECs.

After $4 \mathrm{~h}$ of exposure to $200 \mu \mathrm{g} / \mathrm{ml}$ of S-SiNPs $(50 \mathrm{~nm})$, autophagosomes and ROS production was observed in HaCaT cells. The TEM images revealed that SiNPs were in the cytoplasm and lysosomes, but not in the nucleus. (Liang et al. 2014).

SiNPs (4-13 nm, $62.5 \mu \mathrm{g} / \mathrm{ml})$ induced a time-dependent $(24,48$, and $72 \mathrm{~h})$ reduction in cell viability and increase in oxidative stress (DCF fluorescence and GSH depletion) in the lung fibroblast cell line MRC-5. Compared to control, a significant increase of autophagic vacuoles and LC-3 II/LC3-I ratio was also observed in a time-dependent manner (Voicu et al. 2015). A549 cells, when exposed to 100 and $1000 \mu \mathrm{g} / \mathrm{ml}$ of 20-nm SiNPs, showed threefold and fivefold increase in MDC fluorescence, respectively. In addition, autophagy genes such as ATG-12 and BECN were significantly upregulated (30- and 50-fold, respectively) along with increased production of ROS in cells dosed with $1000 \mu \mathrm{g} / \mathrm{ml}$ (Nowak et al. 2014).

\section{Conclusion: autophagy}

SiNPs, particularly S-SiNPs induced autophagy mainly via oxidative stress-mediated upregulation of autophagyrelated genes and differential regulation of Akt/mTOR signaling. Similar to cytotoxicity, $25 \mu \mathrm{g} / \mathrm{ml}$ appeared to be the lowest exposure concentration at which SiNPs exhibited significant effects. Furthermore, induced autophagy is correlated to cytotoxicity, suggesting that exposure to SiNPs caused irreversible (serious) cellular damage and resulted in autophagic cell death. Besides autophagy induction, lysosomal and autophagy dysfunction could be a potential mechanism of NPs toxicity (Stern et al. 2012), which has, however, not been investigated for SiNPs.

\section{Toxic effects on blood cells and endothelial dysfunction}

Several studies suggest that NPs, when inhaled or ingested, can translocate across barriers (such as air-blood) of the body, enter the circulation, and interact with the cardiovascular system. In this section, we summarized the studies that report the effects of SiNPs on blood and endothelial cells.

\section{Toxic effects on blood cells}

Nemmar et al. (2015) showed that mouse blood platelets could aggregate after $3 \mathrm{~min}$ of incubation with 5 or $25 \mu \mathrm{g} /$ $\mathrm{ml}$ of 50-nm C-SiNPs, while in the study of Jose Corbalan et al. (2012), such aggregation was observed in $15 \mathrm{~min}$
$(10 \mu \mathrm{g} / \mathrm{ml}$ of $10 \mathrm{~nm}$ C-SiNPs). The latter study also showed fourfold reduction of the nitric oxide $(\mathrm{NO}) /$ peroxynitrite $\left(\mathrm{ONOO}^{-}\right)$ratio compared to non-treated platelets.

Maurer-jones et al. (2010) investigated the role of porosity of SiNPs on blood cell toxicity. M-SiNPs $(25 \mathrm{~nm})$ reduced the cell viability of red blood cells (RBCs) to $50 \%$ at the concentration of $270 \mu \mathrm{g} / \mathrm{ml}$, while non-porous S-SiNPs of similar size required only $20 \mu \mathrm{g} / \mathrm{ml}$ to reach this level of cytotoxicity. In another study, $10 \%$ hemolysis $\left(\mathrm{LC}_{10}\right)$ of RBCs was observed at $36 \mu \mathrm{g} / \mathrm{ml}$ for S-SiNPs $(115 \mathrm{~nm})$, while M-SiNPs required $154 \mu \mathrm{g} / \mathrm{ml}$ to induce the same effects. For amine-coated counterparts, $\mathrm{LC}_{10}$ were 97 and $30 \mu \mathrm{g} / \mathrm{ml}$ for S- and M-SiNPs, respectively (Yu et al. 2011).

\section{Endothelium dysfunction}

Exposure to different concentrations $(12.5-100 \mu \mathrm{g} / \mathrm{ml})$ of S-SiNPs $(58 \mathrm{~nm})$ resulted in a dose-dependent increase in inflammatory mediators such as IL-1 $\beta$, IL- 8 , and TNF $\alpha$, intercellular adhesion molecule-1 (ICAM-1), vascular cell adhesion molecule (VCAM-1), and monocyte chemoattractant protein-1 (MCP-1) in HUVEC cells (Guo et al. 2015). In the study of Corbalan et al. (2011), $10 \mu \mathrm{g} / \mathrm{ml}$ of 10-nm C-SiNPs induced extremely low $\mathrm{NO} / \mathrm{NOO}^{-}$ratio $(\sim 0.1)$ in HUVEC cells. Furthermore, free radical production, pro-inflammatory cytokines (IL-6 and IL-8), and NF- $\kappa$ B-binding activity were significantly increased in treated cells. In these two studies, increase in ROS was observed at all tested concentrations.

$\mathrm{S}$-SiNPs $(62 \mathrm{~nm})$ induced an imbalance in the ratio NO/ nitric oxide synthase (NOS) enzyme in HUVEC cells and such imbalance resulted in a significant increase of proinflammatory response (c-reactive protein CRP, IL-1 $\beta$, IL-6, and $\mathrm{TNF} \alpha)$ in a dose- $(50-100 \mu \mathrm{g} / \mathrm{ml})$ dependent manner (Duan et al. 2014b).

\section{Conclusion: Toxic effects on blood cells and endothelial dysfunction}

Endothelial cells and platelets together play a key role in maintaining the vascular homeostasis (Rajendran et al. 2013). C-SiNPs induced oxidative stress and disturbed NO/ $\mathrm{NOO}^{-}$ratio, which resulted in the aggregation of platelets and endothelial dysfunction. This information is not available for other types of SiNPs. Furthermore, C-SiNPs mediated endothelial dysfunction resulted in pro-inflammatory signals via the secretion of cytokines and adhesion molecules. Together, these results suggest the potential of SiNPs to cause vascular thrombosis and atherosclerosis (Radomski et al. 2005). Furthermore, SiNPs caused hemolysis of RBCs in a size-, charge-, and porosity-dependent manner. 


\section{Neurotoxicity}

NPs of very small size are capable of translocating across the blood-brain barrier ( $\mathrm{Hu}$ and Gao 2010). Therefore, studies investigating effects on cells relevant for neurotoxicity are presented here.

Rat medulla tumor cells (PC12 cell line) incubated with the supernatant of $20 \mathrm{~nm}$ SiNPs-treated-microglial cells $(250 \mu \mathrm{g} / \mathrm{ml}$ and $500 \mu \mathrm{g} / \mathrm{ml}$ for $24 \mathrm{~h}$ ) did not show any effects compared to the control. Earlier in this study, no secretion of bio-mediators was observed in SiNPs-treated-microglial cells (Xue et al. 2012). In contrast to this study, PC12 cells exposed directly to SiNPs ( $25 \mathrm{~nm} ; 25-200 \mu \mathrm{g} / \mathrm{ml}$ for $24 \mathrm{~h}$ ) showed increased uptake and a dose-dependent increase in the induction of autophagy (increase in LC-II and Beclin 1) and inhibition of PI3 K-Akt-mTOR signaling (Xie and Wu 2016). Yang et al. (2014a) showed that exposure to SiNPs $(15 \mathrm{~nm} ; 10 \mu \mathrm{g} / \mathrm{ml}$ for $24 \mathrm{~h})$ induced pathological signs of Alzheimer's disease such as altered expression of amyloid precursor protein (APP) and neprilysin, enhanced phosphorylation of tau at Ser262 and Ser396, and activation of glycogen syntheses kinase (GSK)-3 $\beta$ in human SK-N-SH and mouse neuro2a neuroblastoma cells.

\section{Conclusion: neurotoxicity}

In vitro studies used cell lines of CNS-based cells, mainly neuron like cells. Although the data on the neurotoxic effects of SiNPs are very limited, studies above suggest that SiNPs can induce adverse effects including the markers of Alzheimer's disease, when in direct contact with neuroblastoma cells.

\section{Miscellaneous issues}

\section{Influence of cell lines on SiNPs cytotoxicity}

A dose- $(80-640 \mu \mathrm{g} / \mathrm{ml})$ dependent decrease in the viability and increase of apoptosis were observed in HepG2 cells in presence of SiNPs (7 and $20 \mathrm{~nm}$ ), but a significant reduction was observed in normal human liver cells (LC-02) only at the unrealistic dose level of $640 \mu \mathrm{g} / \mathrm{ml}$ (Lu et al. 2011). In another study, SiNPs (10-50 nm) induced a dose-dependent $(100-600 \mu \mathrm{g} / \mathrm{ml})$ increase in LDH release in Caco-2 cells, but a significant release of LDH was observed only at the unrealistic dose of $600 \mu \mathrm{g} /$ $\mathrm{ml}$ in human gastric epithelial cells (GES-1). Furthermore, exposure to these SiNPs $(200 \mu \mathrm{g} / \mathrm{ml}$ for $48 \mathrm{~h}$ ) also induced cell cycle arrest in $\mathrm{S}$ phase for GES cells and G2/M in Caco-2 cells (Yang et al. 2014b). In a porcine kidney cell line (LLC PK1) exposed to 20-nm SiNPs, a dose- $(5-50 \mu \mathrm{g} / \mathrm{ml})$ dependent increase in DCF fluorescence and MDA formation was observed, whereas human kidney cells (HK-2) showed little effects at $50 \mu \mathrm{g} / \mathrm{ml}$ (Passagne et al. 2012).

\section{Conclusion: miscellaneous issues}

No firm conclusions can be drawn from these cases; however, the cytotoxicity of SiNPs appears to vary with species and cell line.

\section{Physiologically relevant cultures}

Lung co-culture models Co-cultures of lung cells are usually made with epithelial cells on the apical and endothelial cells on the basal compartment of a transwell membrane, with or without monocytes on top of the epithelial cells. In a co-culture (A 549 at the apical and ISO-HAS-1 at the basolateral compartment) exposed to $100-\mu \mathrm{g} / \mathrm{ml} 30-\mathrm{nm}$ C-SiNPs (coated with or without surfactant), nearly a fivefold increase of IL-8 release for both forms of SiNPs was observed in both compartments (Kasper et al. 2015). When other epithelial cells were used-H441 cells-at the apical together with ISO-HAS- 1 cells at the basolateral compartment, these C-SiNPs induced IL-8 were expressed in both compartments, while SiCAM-1 $(6-600 \mu \mathrm{g} / \mathrm{ml})$ and IL-6 (at 6 and $60 \mu \mathrm{g} / \mathrm{ml}$ ) were observed only in the apical part (Kasper et al. 2011). The same co-culture model was exposed to $100 \mu \mathrm{g} /$ $\mathrm{ml}$ of S-SiNPs $(15,35$, and $80 \mathrm{~nm})$ and the authors noticed an increase of IL-8, TNF- $\alpha$, and surfactant protein (SP-A1 and SP-A2) expression compared to the control. In addition, less IL- 8 and surfactant protein expression, and more TNF- $\alpha$ were observed in the co-culture added with THP-1, notably the effect was the highest for $35 \mathrm{~nm}$ (Farcal et al. 2012).

Napierska et al. (2012b) tested SiNPs with primary size $2,16,60$, and $104 \mathrm{~nm}\left(\right.$ dosed at $\left.10 \mu \mathrm{g} / \mathrm{cm}^{2}\right)$ in a coculture (A549 at the apical and EA. hy926 at the basolateral compartment) and observed increase in cytokines such as IL-6, IL-8, TNF- $\alpha$, and MIP- $1 \alpha$ only for 60 and $2 \mathrm{~nm}$ (except IL-8). When THP-1 were added to the coculture, a significant increase in IL-8 and decrease in TNF- $\alpha$ were observed only for $2 \mathrm{~nm}$. The expression of cytokines was also differentially regulated for 16 and $104 \mathrm{~nm}$ before and after THP-1 added, but the effects were stronger for 60 and $2 \mathrm{~nm}$, particularly 60-nm NPs.

Air-liquid interface At the air-liquid interface (ALI), aerosolized and deposited 12-nm Py-SiNPs $\left(52 \mu \mathrm{g} / \mathrm{cm}^{2)}\right.$ and 50-nm S-SiNPs $\left(117 \mu \mathrm{g} / \mathrm{cm}^{2}\right)$ induced significantly less biological effects (LDH leakage, IL- 8 release, COX-2 expression, and p38 phosphorylation) in A549 cells compared to A549 exposed to $15.6 \mu \mathrm{g} / \mathrm{cm}^{2}$ under sub-merged conditions (Panas et al. 2014). 


\section{Conclusion: physiologically relevant cultures}

Sub-merged (co) cultures and ALI systems (Lenz et al. 2013; Panas et al. 2014) have been claimed to more closely mimicking the in vivo exposure scenarios compared to monocultures. In these systems, the toxicity and pro-inflammatory responses are significantly modulated by SiNPs, which represent the complexity of in vivo systems and need for the establishment of physiologically relevant in vitro cultures. However, at this moment, it is difficult to know whether these biological responses were influenced by SiNPs physico-chemical properties.

\section{Chronic in vitro studies}

In vitro chronic Py-SiNPs (12 nm) exposure of intestinal epithelial cell line $(\mathrm{C} 2 \mathrm{BBe} 1)$ was examined in a recent study. The cells were exposed to $10-\mu \mathrm{g} / \mathrm{cm}^{2}$ SiNPs for $24 \mathrm{~h}$. After $24 \mathrm{~h}$, the medium was replaced (without NPs) and cells were allowed to grow for 4-6 days. At the end of incubation, cells were passaged and again exposed for $24 \mathrm{~h}$ and grown for 4-6 days; this cycle was repeated for 29 passages (total life span). The cells and supernatants were collected at the end of each passage for analysis. Though the particles were internalized (only in a fraction of cells), no significant induction of necrosis, apoptosis, and LDH release and decrease in cell viability was observed for any of these conditions (McCracken et al. 2013).

\section{In vivo studies}

\section{Ingestion exposure}

\section{Single exposure}

Lee et al. (2014) investigated the tissue distribution and excretion profiles in Sprague-Dawley (SD) rats orally administered with a very high dose of 500 or $1000-\mathrm{mg} / \mathrm{kg}$ bw of C-SiNPs (20 and $100 \mathrm{~nm}$ ). Silicon (Si) levels were significantly elevated in liver, kidney, lung, and spleen at 6-h post-administration, while no such increase was noticed in brain, ovaries or testes, esophagus, stomach, and intestine even after 7 days of post-administration. Nearly $75-80 \%$ of administered SiNPs were excreted via urine and $7-8 \%$ via feces. The author also noticed that $20 \mathrm{~nm}$ SiNPs excreted faster than the $100 \mathrm{~nm}$ SiNPs. In another study, C-SiNPs $(12 \mathrm{~nm})$ did not induce any toxicity after 14 days in SD-rats administered with a single oral dose (1959 or $2061 \mathrm{mg} / \mathrm{kg} \mathrm{bw}$ ) (Yun et al. 2015).

In the study of Li et al. (2015), M-SiNPs with different aspect ratios (AR, spherical $83 \mathrm{~nm}$ with AR 1, short rods with AR 1.75 and long rods with AR 5) were administered in mice ( $40 \mathrm{mg} / \mathrm{kg}$ bw via gavage). After 7 days, a very high amount of Si was detected only in the liver of spherical SiNPs exposed mice. Urinary excretion, intestinal absorption, and organ distribution of SiNPs were decreased with increasing aspect ratio. Furthermore, increase in renal damage such as hemorrhage, vascular congestion, and renal tubular necrosis with increasing aspect ratio was observed after 14 days of administration.

Kim et al. (2014b) exposed C57BL/6 mice (oral gavage; $750 \mathrm{mg} / \mathrm{kg} \mathrm{bw}$ ) to C-SiNPs (20 and $100 \mathrm{~nm}$ ) that had been modified with or without $\mathrm{L}$-arginine to determine the influence of surface charge on immunotoxicity in vivo. After 14 days, the author noticed a size-dependent decrease in WBCs cell count and cytokines (in blood), and reduced proliferation of $\mathrm{B}$ cells and $\mathrm{T}$ cells (from spleen) only for uncoated SiNPs.

\section{Repeated exposure}

C-SiNPs $(12 \mathrm{~nm})$ neither induce abnormal changes in blood biochemical and hematological parameters nor accumulated in any organs of the acutely $(489.8,979.5$, or $1959 \mathrm{mg} / \mathrm{kg}$ bw/day, during 14 days) or sub-chronically (244.9, 489.8, or $975.9 \mathrm{mg} / \mathrm{kg}$ bw/day, during 13 weeks) exposed (via gavage) SD rats (Yun et al. 2015). In the study by Kim et al. (2014c), C-SiNPs (20 and $100 \mathrm{~nm}$ ) did not induce any significant changes (compared to control) in clinical signs, blood biochemical, hematological, and histopathological analysis in sub-chronically exposed Crl: CD (SD) specific pathogen-free rats $(500,1000$, or $2000 \mathrm{mg} / \mathrm{kg}$ bw/day for 90 days).

SD rats were administered (via oral gavage) with low doses $(5,10$ or $20 \mathrm{mg} / \mathrm{kgbw})$ of Pr-SiNPs (NM 200 and 201) and Py-SiNPs (NM 202 and 203) at 0, 24 and $45 \mathrm{~h}$ and sacrificed at $3 \mathrm{~h}$ after the last administration. No significant genotoxicity was observed in cells extracted from different organs (duodenum, colon, blood, kidney, liver, and spleen), and no pathological conditions were recorded in any of these organs (Tarantini et al. 2015a).

Hofmann et al. (2015) investigated the prenatal toxicity by exposing pregnant Wistar rats to Pr-SiNPs (NM 200) from gestation day 6-19. At doses of 100 , 300, or $1000 \mathrm{mg} / \mathrm{kgbw} / \mathrm{day}$, administered SiNPs did not induce malformations in fetuses or death of the rats.

Zande et al. (2014) investigated the sub-acute and subchronic toxicity of Py-SiNPs (7 nm) and NM-202 (10$25 \mathrm{~nm}$ ). In the sub-acute part, male SD rats were orally (via food) exposed to 100,1000 , or $2500 \mathrm{mg}$ Py-SiNPs/ $\mathrm{kg}$ bw/day for 28 days, while in the sub-chronic part, the rats were exposed only to the highest dose $(2500 \mathrm{mg} / \mathrm{kg}$ bw/day) repeatedly for 84 days. ICP-MS analysis of target 
organs showed that NM-202 was significantly distributed in the lung, kidney, and spleen. Although no Si was detected in the liver, histopathological analysis and gene expression studies revealed that fibrosis was induced in the liver after 84 days of exposure. Si was found in the spleen of Py-SiNPs exposed rats only at the end of chronic exposure. The examined parameters such as blood biochemistry, antibody levels (IgG and IgM), and cytokines indicated no systemic toxicity in any of the Py- or NM-202 treated rats.

Yoshida et al. (2014) found an increased intestinal absorption of carboxyl (twofold) and amine-coated SiNPs (1.5-fold) compared to uncoated SiNPs $(70 \mathrm{~nm})$ in orally exposed BALB/c mice ( $2.5 \mathrm{mg} / \mathrm{mouse} /$ day for 28 days). In this study, the whole small intestine was processed using the everted gut sac method and a significant amount of $\mathrm{Si}$ was detected by ICP-MS. However, no signs of systemic toxicity were observed for any of these SiNPs.

In male Wistar rats that exposed to $10-15 \mathrm{~nm}$ SiNPs (oral gavage; $333.3 \mathrm{mg} / \mathrm{kg}$ bw/day for 5 days), histopathological analysis revealed gross tissue damage in kidney (cell swelling and necrosis), lung (interstitial pneumonia and bronchopneumonia), and in the testis (congestion, reduction of spermatogenesis and edema). In addition, blood biochemical parameters such as albumin, cholesterol, triglycerides, total proteins, urea, high-density lipoprotein (HDL), and low-density lipoprotein (LDL), as well as alkaline phosphatase (ALP) and aspartate aminotransferase (AST) activities were significantly increased in treated mice (Hassankhani et al. 2014).

\section{Inhalation exposure}

\section{Single exposure}

In the study of Morris et al. (2016), C57BL/6 mice were intratracheally instilled with 4- or 20-mg S-SiNPs/kg bw and significant effects were observed only at the dose of $20 \mathrm{mg} /$ $\mathrm{kg}$. Twenty hours after instillation, approximately 20- and 10-fold higher cell number was observed in the bronchoalveolar lavage (BAL) of mice treated with the bare and aminecoated SiNPs, respectively, compared to control mice; neutrophils were also increased about 30- and 20-fold, respectively.

In another study, 15- and 55-nm C-SiNPs neither induced DNA damage nor micronuclei in lung and bone marrow (erythrocytes) cells of Wistar rats at $72 \mathrm{~h}$ of postinstillation $(360 \mu \mathrm{g})$ (Maser et al. 2015). However, the distribution of administered SiNPs to these organs was not investigated.

\section{Repeated exposure}

A size- and dose-dependent increase in the distribution of SiNPs was observed in the serum and heart of male
Wistar rats intratracheally instilled $(2,5$, or $10 \mathrm{mg} / \mathrm{kg}$ bw/ day for 16 days) with SiNPs (30, 60, 90, and $300 \mathrm{~nm}$ ). Blood parameters (WBCs and platelets), inflammatory bio-markers (TNF- $\alpha$, IL-1 $\beta$, and IL-6), and oxidative stress bio-markers (ROS and MDA formation) were significant increased, while NO, NOS, and eNOS were significantly decreased in the serum of the treated mice (Du et al. 2013).

A study compared the toxicity and biodistribution of pristine SiNPs $(19 \mathrm{~nm})$ and aged paints containing SiNPs in BALB/c mice. The suspensions ( $20 \mu \mathrm{g} /$ aspiration) were oropharyngeally aspirated once a week for 5 weeks, and mice were sacrificed either at 2- or at 28-day post-final aspiration treatment. Pristine SiNPs were significantly distributed in the lungs and liver, while only a low amount of $\mathrm{Si}$ was detected in the liver of paint-exposed mice. No signs of toxicity were observed, except a slight inflammation (a slight increase in macrophages and neutrophils together with an increase of IL-1 $\beta$ ) with pristine SiNPs (Smulders et al. 2014).

Male Wistar rats were intranasally instilled with $150 \mu \mathrm{g}$ SiNPs $(10$ and $80 \mathrm{~nm})$ repeatedly for 30 days. After 30 days, a size-dependent increase in the levels of hydrogen peroxide $\left(\mathrm{H}_{2} \mathrm{O}_{2}\right)$, MDA formation, TNF- $\alpha$, IL-1 $\beta$, MCP-1, and NF- $\mathrm{\beta} \beta$ was observed in the frontal cortex, corpus striatum, and hippocampus of the brain. A similar quantity of $\mathrm{Si}$ was detected in all these three regions. In addition, a significant decrease in GSH levels was observed in these tissues (Parveen et al. 2015). The latter study shows the potential translocation of (mainly small) SiNP from the nose to the brain, but it has to be noted that the mice received a high dose during 30 days.

Intratracheally administered $(2 \mathrm{mg} / \mathrm{kg}$ bw; 15 times, once every 3 days) S-SiNPs (58 nm) resulted in reproductive toxicity in $\mathrm{C} 57$ mice via enhanced ROS production and cell cycle arrest (G0/G1 phase) in the testicular tissues, and by decreasing the number of mature sperms and primary spermatocytes (Zhang et al. 2016). In another study, repeated intracheal instillation of S-SiNPs $(58 \mathrm{~nm} ; 0,7$, 21 , and $35 \mathrm{mg} / \mathrm{kg}$ bw; 5 times, once every 3 days) induced local (macrophage activation in lung, liver, and spleen) and systemic inflammation (Increase in serum IL-8, TNF- $\alpha$, and IL-6) in BALB/c mice. In addition, SiNPs were also detected in the lysosomes of macrophages in lung, liver, and heart tissues (Yang et al. 2016).

\section{Dermal exposure}

\section{Repeated exposure}

The skin of SD rats was repeatedly exposed to different doses $(500,1000 \mathrm{mg}$, or $2000 \mathrm{mg} / \mathrm{kg} \mathrm{bw})$ of L-arginine coated C-SiNPs $(20 \mathrm{~nm})$ for 90 days (6-h exposure/day). The repeated exposure neither induced gross changes in 
the skin nor in any organs. In addition, hematological and blood biochemical parameters did not change in SiNPstreated mice compared to controls (Ryu et al. 2014). In another study, Shim et al. (2014) showed that C-SINPS (20 and $100 \mathrm{~nm}$ ) did not induce toxicity in the right and left brain or distribution in the cerebellum, hippocampus, or striatum of the dermally exposed rats (1000 or $2000 \mathrm{mg}$ / kgbw daily for 90 days). In contrast to these studies, a significant increase in apoptosis (TUNEL positive cells) was observed in the skin of the BALB/c mice topically exposed to $70-\mathrm{nm}$ SiNPs ( $250 \mathrm{mg} / \mathrm{ear} / \mathrm{day}$ for 28 days). The author reported that the SiNPs were found not only in the skin but also in the regional lymph nodes, cerebral cortex, hippocampus, and in the liver (Nabeshi et al. 2011b).

\section{Parenteral exposure}

\section{Single exposure}

In a 48-h study, exposure to $15-\mathrm{nm}$ SiNPs (dose of $50 \mathrm{mg}$ / $\mathrm{kg}$ bw by intravenous injection) resulted in a significant increase of CD68-positive Kupffer cells (KCs), WBCs, lymphocytes, monocytes, neutrophils, and TNF- $\alpha$ in the serum of male SD rats. There was a decrease in GSH activity and elevation in MDA levels in the liver of treated mice. Furthermore, bio-markers of liver dysfunction such as lactate, phosphorylcholine, sn-glycero-3-phosphocholine, tyrosine, phenylalanine, and lysine were increased in blood, while the levels of succinate, glucose, and glycine were significantly decreased in mice exposed to SiNPs (Chen et al. 2013).

In another study, $50 \mathrm{~nm} \mathrm{C-SiNPs}(0.25 \mathrm{mg} / \mathrm{kg} \mathrm{bw})$ induced a significant increase in blood parameters such as leukocyte number, creatinine kinase (CK), ALT, AST, and LDH release in male tuck ordinary mice at 24-h postintraperitoneal injection. Oxidative stress bio-markers such as MDA formation, SOD, and catalase were significantly increased in the lungs, liver, kidney, and brain of SiNPstreated mice. Cytokines such as IL- 6 , IL- $1 \beta$, and TNF- $\alpha$ were significantly increased in the lung and differentially expressed in other organs. Furthermore, all organs showed a significant DNA damage compared to saline treated mice and the extent of damage was in the order heart $>$ kidney $>$ lung $>$ liver $>$ brain (Nemmar et al. 2016).

In the study of Duan et al. (2014a, b), ICR mice were intravenously injected with $29.5,103.5$, or $177.5 \mathrm{mg} / \mathrm{kg}$ bw of $62 \mathrm{~nm} \mathrm{S-SiNPs.} \mathrm{After} 14$ days, induction of autophagic vacuoles and mitochondrial rupturing in the heart tissues was observed using TEM. In addition, increase in LC3 positive staining in the heart tissues was detected at 103.5 and $177.5 \mathrm{mg} / \mathrm{kg}$ bw, and the expression of ICAM-1 and VCAM-1 was significantly decreased at $177.5 \mathrm{mg} / \mathrm{kg}$. Huang et al. (2011) injected the mice intravenously with mesoporous rods (pure or PEGylated) at a dose of $20 \mathrm{mg} /$ $\mathrm{kg}$ bw and found a dysfunction in biliary excretion and glomerular filtration. Blood analysis showed that there was a significant increase in total bilirubin (TBIL), blood urea nitrogen (BUN), and creatinine (CREA). The mesoporous rods mainly distributed in the lung, liver, and spleen, but PEGylation significantly reduced their distribution in these organs. In addition, short rods cleared via urine and feces more rapidly than long rods.

Yu et al. (2013) estimated the i.v. median lethal dose $\left(\mathrm{LD}_{50}\right)$ for $64 \mathrm{~nm} \mathrm{C-SiNPs}$ as $262 \mathrm{mg} / \mathrm{kg}$ bw in ICR mice using the Dixon's Up and Down method. After 14-day postadministration, intravenously injected C-SiNPs $(64 \mathrm{~nm}$, $177.5 \mathrm{mg} / \mathrm{kg} \mathrm{bw}$ ) induced a significant increase in liver injury bio-markers (LDH, AST, and ALT). Histopathological analysis of target organs showed that the number of megakaryocytes in the spleen was significantly increased, and pulmonary hyperemia and interstitial thickening were observed in the lungs. Nearly $35 \%$ of the injected SiNPs were distributed in the spleen, $12.5 \%$ in the liver, and $2 \%$ in the lung of SNP-treated mice.

At $24 \mathrm{~h}$ of post-intravenous administration $(30 \mathrm{mg} / \mathrm{kg}$ bw), TEM imaging of the BALB/c mice tissues showed that 70-nm SiNPs were localized in the regional lymph nodes, cerebral cortex, hippocampus, and the cytoplasm, and nucleus of hepatocytes (liver). Using in vivo imaging, the authors also found that the SiNPs were distributed near the liver immediately after the administration (20 min) and moved near the intestinal tract over time $(6 \mathrm{~h})$. Micronsized silica particles (300 and $1000 \mathrm{~nm}$ ) used in these studies were accumulated mainly around the gall bladder (Nabeshi et al. 2011b).

A significant increase in the levels of kidney injury bio-markers such as BUN and CREA and morphological changes associated with renal interstitial fibrosis was noticed in BALB/c mice intraperitoneally treated with $198-\mathrm{nm}$ M-SiNPs $(150,300$, or $600 \mathrm{mg} / \mathrm{kg}$ bw for 2 or 12 days). There was also a significant increase in the levels of fibronectin (FN), TGF- $\beta$ and ICAM- 1 , and nuclear translocation of p65 in 300- or $600-\mathrm{mg} / \mathrm{kg}$ treated mice (Chen et al. 2015).

Zhuravskii et al. (2016) demonstrated that intravenously injected $(70 \mathrm{mg} / \mathrm{kg}$ bw) Py-SiNPs $(13 \pm 5 \mathrm{~nm})$ distributed and persisted in the liver of Wistar rats at 60-day postadministration. The authors also indicated that the administered SiNPs induced fibrosis and liver tissue remodeling by noticing the increase in blood ALT, and presence of mast cells, connective tissues, and foreign body-type granulomas in the liver.

\section{Conclusion: in vivo}

The in vivo toxicity studies have been carried out using rats and mice, and exposure through various routes of 
administration. In general, short-term exposure to SiNPs induced adverse effects in the lungs, kidneys, liver, and brain. SiNPs administered mainly via inhalation, ingestion, and intravenous routes were majorly distributed in the liver, lungs, spleen, and kidneys, and in the brain of the intranasally exposed rats. Most of the administered SiNPs were excreted via feces and to a lesser extent via urine, in a size- and shape-dependent manner. However, in most cases, the administered doses were very high compared to relevant human inhalation (Barsan 2007) and ingestion (Winkler et al. 2016; Dekkers et al. 2011) exposures to amorphous silica. Some studies showed accumulation of SiNPs in organs such as the liver, but such accumulation was not associated with any major effects. However, long-term effects of accumulated SiNPs were not studied. It is surprising that in contrast to acute studies, no toxicity (local or systemic) was observed in chronic oral and dermal exposure studies, regardless of the size of SiNPs and the high doses used. Moreover, surface-modified SiNPs showed a significant increase in absorption by the GI tract compared to bare SiNPs. Dosing SiNPs via i.v. showed in all studies some sign of damage/toxicity. No clear typeor size-dependent effect can be identified from the set of reviewed studies. Furthermore, where genotoxicity was studied, it was not clear whether SiNPs were taken up by the target cells or were able to reach the tissue examined, which is obviously needed to exert a direct genotoxic effect.

\section{Discussion}

Growing production and use of SiNPs increase the risk of human exposures. Available toxicity studies mainly focused on effects after exposure via inhalation or skin (occupational exposure), ingestion (food additive), or nano-therapeutics (parenteral exposure). In vitro and in vivo studies demonstrated that SiNPs can induce adverse effects, but multiple 'inconsistencies' were found in the collected toxicity data set. As small differences in the physico-chemical properties of SiNPs could contribute to significant variation in the toxicity (Napierska et al. 2010), it is critical to discriminate how these variations influence toxicity. It is also worthy to note that the choice of cell type, culture system, assay conditions (Fede et al. 2012; Geys et al. 2010; Hayashi et al. 2017), and exposure route influence the toxic responses to SiNPs. However, the nature of these variations remains unclear, which continues to limit our understanding of SiNPs toxicity and hampers their hazard assessment.

\section{Physico-chemical characterization}

In this review, a basic set of physico-chemical characteristics of primary SiNPs such as primary size, shape, crystallinity, and chemical composition (or) purity was set as inclusion criteria. Most studies associated the toxic endpoints to SiNPs size, while only a few related the toxicity to SiNPs porosity, shape, surface charge, and surface chemistry. Furthermore, hydrodynamic diameter is another widely reported property in these studies and the results suggest that, in most cases, SiNPs are often aggregated/agglomerated (AA) in cell culture media. Conversely, AA formation is also very likely in real-world matrices such as in air (Kim et al. 2014a), water, and in commercial products such as food (Dekkers et al. 2011). Such AA formation not only substantially alters the overall characteristics (such as size, shape and surface topology) but also potentially influences the biological outcomes (Luyts et al. 2013; Drescher et al. 2011). Although some progress has been made in the characterization of SiNPs AA in recent years (De Temmerman et al. 2012), their biological effects remain poorly understood.

\section{Toxicity of different types of SiNPs}

Synthetic amorphous SiNPs are produced via different methods such as thermal (pyrogenic) or wet route (colloidal, precipitated and gel). The physico-chemical characteristics of SiNPs produced by these methods differ (Fruijtier-Pölloth 2012; Napierska et al. 2010) and may influence the biological outcomes. In this review, nearly $70 \%$ of the papers clearly reported the synthesis method. Among those $70 \%$, about $80 \%$ reported the toxicity of wet method based SiNPs and only approximately $20 \%$ on the other types (such as pyrogenic and mesoporous). A general overview of toxic effects induced by different types of SiNPs is presented in Table 3. Cytotoxicity and genotoxicity induced by S- and C-SiNPs are strongly correlated with the induction of oxidative stress. For PrSiNPs, oxidative stress was associated with cytotoxicity but not genotoxicity. Interestingly, Py-SiNPs caused cytotoxicity, mostly without the generation of oxidative stress. In addition, recent studies showed that Py-SiNPs are biologically more reactive than C-SiNPs (Zhang et al. 2012) and Pr-SiNPs (Di Cristo et al. 2016) of same composition and size. It is known that C-, S-, and Pr-SiNPs are hydrophilic in nature, while Py-SiNPs are hydrophobic due to the de-hydroxylation of surface $\mathrm{OH}$ groups during the production process (Napierska et al. 2010), 
and such difference in surface chemistries might contribute to different biological activities. However, more systematic studies are required to verify these differences depending on production processes.

\section{Toxicity mechanisms of amorphous SiNPs and crystalline silica}

A fundamental question was raised by Napierska et al. (2010): do amorphous SiNPs induce biological responses similar to crystalline silica? Oxidative DNA and membrane damage have been reported as the major toxic mechanisms involved in the health effects of micron-sized crystalline silica, which is also observed for C- and Pr-SiNPs. The latter two possess silanols on the surface while Py-SiNPs mostly contain siloxanes (Napierska et al. 2010). In addition, recent studies showed that the presence of surface moieties such as silanols is more correlated with crystalline silica toxicity than crystallinity (Zhang et al. 2012; Turci et al. 2016). Thus, silanols appear to be a common surface feature in C-SiNPs, Pr-SiNPs, and crystalline silica, which might contribute to a similar toxic activity. Furthermore, toxicity elicited by PySiNPs appears to be oxidative stress-independent, indicating that Py-SiNPs induce adverse effects via other mechanisms (Gehrke et al. 2013; Napierska et al. 2012a). More studies are required to verify these hypotheses.

\section{Influence of exposure routes in vivo}

The exposure route obviously influences the in vivo absorption, biodistribution, and toxicity of SiNPs. For instance, after oropharyngeal aspiration or intratracheal instillation, the lungs are clearly the main target (Smulders et al. 2014), while after ingestion (Zande et al. 2014) or iv injection (Yu et al. 2013), the liver and/or the spleen were the targets. SiNPs accumulated in the brain of intranasally exposed rats (Parveen et al. 2015) but did not after oral exposure (Shim et al. 2014). In addition to the exposure route, physicochemical properties such as size and shape clearly influence the clearance, distribution, and toxicity (Huang et al. 2011; Li et al. 2015).

\section{Adverse effects of chronic exposure in vivo}

In repeated (oral and dermal) dose studies ( $\geq 28$ days), SiNPs did not induce any local or systemic toxicity even in (very) highly dosed rats. A recent study demonstrated that mild and highly dosed rats excreted most of the orally administered SiNPs via the feces (Yun et al. 2015). In addition, Van der Zande et al. (2014) demonstrated the in vitro gelation of SiNPs with increasing concentrations, which might reduce the gastro-intestinal absorption in highly dosed animals and increase excretion via feces. Therefore, the use of (low) realistic exposure doses appears more appropriate, since the toxicokinetics may depend on the level of exposure (Paek et al. 2014). Moreover, information on the physico-chemical properties of ingested and digested SiNPs is lacking, representing a huge knowledge gap in the risk assessment of SiNPs in food (Dekkers et al. 2012).

\section{Correlation between in vitro and in vivo studies}

Correlation between in vitro and in vivo effects is an indication that specific cells or tissues are potential targets for SiNPs toxicity. The results of in vitro and in vivo experiments (included within the same study) suggest that exposure to SiNPs could induce Kupffer cell mediated liver injury (Chen et al. 2013), kidney injury via the activation of NF-kB signaling pathways (Chen et al. 2015), and endothelial dysfunction via autophagy (Duan et al. 2014a). Several in vitro studies showed that SiNPs caused DNA double-strand breaks in a wide range of immortalized cell lines at low doses, but no such genotoxic effects were observed, even in animals at high doses. In addition, SiNPs did not induce micronuclei either in vitro or in vivo.

\section{Dosimetry in vitro}

Accurate in vitro dosimetry is an important yet complex aspect of nanotoxicology (Lison et al. 2014). In many studies reviewed here, authors often tested high in vitro exposure doses. Considering the exposure dose as nominal dose may be appropriate only for well dispersed and stable SiNP suspensions (Lison et al. 2008). However, Py-SiNPs, for instance, often re-agglomerate in culture media with an effective density lower than the material density (Deloid et al. 2014), thereby potentially affecting the dose reaching the cells (Cohen et al. 2014). Thus, a realistic estimation of the delivered dose is necessary to compare the biological effects between studies and to establish good in vitro and in vivo correlations ( $\mathrm{Pal}$ et al. 2015).

\section{Physico-chemical properties for the safer design of SiNPs}

Immune responses after the administration of SiNPs are very crucial, as they can induce cascades of events by the secretion of cytokines, which may be harmful or beneficial. The data collected in this review show that the smaller the size, the stronger the pro-inflammatory effect. In addition to the size, the surface charge appears to play a role, since less negative charges seem to suppress the immune response. Porosity is another crucial factor influencing 
blood biocompatibility, i.e., the more porous the SiNPs, the less hemolysis of RBCs (Maurer-jones et al. 2010). Furthermore, SiNPs aspect ratio was shown to closely relate to in vivo organ retention and clearance (Huang et al. 2011). Therefore, the size, surface area, porosity, and geometry (shape) appear to be the key parameters for designing lesstoxic and less-inflammagenic SiNPs, for bio-medical applications for instance.

In conclusion, SiNPs generally exhibit acute toxic effects in vitro and in vivo. The data on chronic effects of SiNPs exposure are rather conflicting with the acute effects and are still insufficient to draw firm conclusions. No concrete data were found to conclude whether amorphous SiNPs induce fibrosis like micrometric crystalline silica. Moreover, translation to human health effects is impossible at this moment due to the lack of realistic exposure and epidemiological data. Surface moieties (such as silanols, silanolates, and siloxanes) of SiNPs are found to be production process-specific and seem to be the key determinants of SiNPs toxicity. AA formation for some SiNPs is very dynamic in physiological media, but it is still unclear how it contributes to the hazard characterization. Therefore, the design of safe(r) SiNPs for food, medical, and other applications will only be possible when physico-chemical characteristics can be unambiguously linked to toxicity. Furthermore, detailed investigations on the SNP bioaccumulation/bioavailability and their long-term consequences in vivo are required for a safer use.

Acknowledgements This work was funded by Belgian Science Policy (BELSPO) program "Belgian Research Action through Interdisciplinary Network (BRAIN-be)" for the project "Towards a toxicologically relevant definition of nanomaterials (To2DeNano)".

\section{Compliance with ethical standards}

Conflict of interest The authors declare that they have no conflict of interest.

Open Access This article is distributed under the terms of the Creative Commons Attribution 4.0 International License (http://creativecommons.org/licenses/by/4.0/), which permits unrestricted use, distribution, and reproduction in any medium, provided you give appropriate credit to the original author(s) and the source, provide a link to the Creative Commons license, and indicate if changes were made.

\section{References}

Ahamed M (2013) Silica nanoparticles-induced cytotoxicity, oxidative stress and apoptosis in cultured A431 and A549 cells. Hum Exp Toxicol 32:186-195. doi:10.1177/0960327112459206

Ahmad J, Ahamed M, Akhtar MJ et al (2012) Apoptosis induction by silica nanoparticles mediated through reactive oxygen species in human liver cell line HepG2. Toxicol Appl Pharmacol 259:160168. doi:10.1016/j.taap.2011.12.020

Arts JHE, Muijser H, Duistermaat E et al (2007) Five-day inhalation toxicity study of three types of synthetic amorphous silicas in Wistar rats and post-exposure evaluations for up to 3 months. Food Chem Toxicol 45:1856-1867. doi:10.1016/j. fct.2007.04.001

Athinarayanan J, Periasamy VS, Alsaif MA et al (2014) Presence of nanosilica (E551) in commercial food products: TNF-mediated oxidative stress and altered cell cycle progression in human lung fibroblast cells. Cell Biol Toxicol 30:89-100. doi:10.1007/ s10565-014-9271-8

Barsan ME (2007) NIOSH pocket guide to chemical hazards. Department of Health and Human Services, Center for Disease Control and Prevention, DHHS (NIOSH). Publication No. 2005149. NIOSH Publications, US

Bitar A, Ahmad NM, Fessi H, Elaissari A (2012) Silica-based nanoparticles for biomedical applications. Drug Discov Today 17:1147-1154. doi:10.1016/j.drudis.2012.06.014

Brinch A, Hansen S, Hartmann N et al (2016) EU regulation of nanobiocides: challenges in implementing the biocidal product regulation (BPR). Nanomaterials 6:33. doi:10.3390/ nano6020033

Chen Q, Xue Y, Sun J (2013) Kupffer cell-mediated hepatic injury induced by silica nanoparticles in vitro and in vivo. Int $\mathbf{J}$ Nanomed 8:1129-1140. doi:10.2147/IJN.S42242

Chen X, Zhouhua W, Jie Z et al (2015) Renal interstitial fibrosis induced by high-dose mesoporous silica nanoparticles via the NF-kappaB signaling pathway. Int J Nanomedicine 10:1-22. doi:10.2147/IJN.S73538

Choi J, Zheng Q, Katz HE, Guilarte TR (2010) Silica-based nanoparticle uptake and cellular response by primary microglia. Environ Health Perspect 118:589-595. doi:10.1289/ ehp.0901534

Chu Z, Huang Y, Li L et al (2012) Physiological pathway of human cell damage induced by genotoxic crystalline silica nanoparticles. Biomaterials 33:7540-7546. doi:10.1016/j. biomaterials.2012.06.073

Cohen JM, Teeguarden JG, Demokritou P (2014) An integrated approach for the in vitro dosimetry of engineered nanomaterials. Part Fibre Toxicol 11:20. doi:10.1186/1743-8977-11-20

Corbalan JJ, Medina C, Jacoby A (2011) Amorphous silica nanoparticles trigger nitric oxide/peroxynitrite imbalance in human endothelial cells : inflammatory and cytotoxic effects. Int $\mathbf{J}$ Nanomed. doi:10.2147/IJN.S25071

Croissant JG, Fatieiev Y, Khashab NM (2017) Degradability and clearance of silicon, organosilica, silsesquioxane, silica mixed oxide, and mesoporous silica nanoparticles. Adv Mater. doi:10.1002/adma.201604634

De Temmerman P-J, Van Doren E, Verleysen E et al (2012) Quantitative characterization of agglomerates and aggregates of pyrogenic and precipitated amorphous silica nanomaterials by transmission electron microscopy. J Nanobiotechnol 10:24. doi:10.1186/1477-3155-10-24

Dekkers S, Krystek P, Peters RJB et al (2011) Presence and risks of nanosilica in food products. Nanotoxicology 5:393-405. doi: 10.3109/17435390.2010.519836

Dekkers S, Bouwmeester H, Bos PMJ et al (2012) Knowledge gaps in risk assessment of nanosilica in food : evaluation of the dissolution and toxicity of different forms of silica. Nanotoxicology. doi:10.3109/17435390.2012.662250

Deloid G, Cohen JM, Darrah T et al (2014) Estimating the effective density of engineered nanomaterials for in vitro dosimetry. Nat Commun 5:3514. doi:10.1038/ncomms4514

Demir E, Castranova V (2016) Genotoxic effects of synthetic amorphous silica nanoparticles in the mouse lymphoma assay. 
Toxicol ReportsToxicol Rep 3:807-815. doi:10.1016/j. toxrep.2016.10.006

Di Cristo L, Movia D, Bianchi MG et al (2016) Proinflammatory effects of pyrogenic and precipitated amorphous silica nanoparticles in innate immunity cells. Toxicol Sci 150:40-53. doi:10.1093/toxsci/kfv258

Donaldson K, Poland CA, Schins RPF (2010) Possible genotoxic mechanisms of nanoparticles: criteria for improved test strategies. Nanotoxicology 4:414-420. doi:10.3109/17435390.201 0.482751

Drescher D, Orts-Gil G, Laube G et al (2011) Toxicity of amorphous silica nanoparticles on eukaryotic cell model is determined by particle agglomeration and serum protein adsorption effects. Anal Bioanal Chem 400:1367-1373. doi:10.1007/ s00216-011-4893-7

Du Z, Zhao D, Jing L et al (2013) Cardiovascular toxicity of different sizes amorphous silica nanoparticles in rats after intratracheal instillation. Cardiovasc Toxicol 13:194-207. doi:10.1007/s12012-013-9198-y

Duan J, Yu Y, Li Y et al (2013a) Toxic effect of silica nanoparticles on endothelial cells through DNA damage response via Chk1dependent G2/M checkpoint. PLoS One. doi:10.1371/journal. pone. 0062087

Duan J, Yu Y, Li Y et al (2013b) Cardiovascular toxicity evaluation of silica nanoparticles in endothelial cells and zebrafish model. Biomaterials 34:5853-5862. doi:10.1016/j. biomaterials.2013.04.032

Duan J, Yu Y, Yu Y et al (2014a) Silica nanoparticles enhance autophagic activity, disturb endothelial cell homeostasis and impair angiogenesis. Part Fibre Toxicol 11:50. doi:10.1186/ s12989-014-0050-8

Duan J, Yu Y, Yu Y et al (2014b) Silica nanoparticles induce autophagy and endothelial dysfunction via the PI3K/Akt/mTOR signaling pathway. Int J Nanomed. doi:10.2147/IJN.S71074

Eom H-J, Choi J (2011) $\mathrm{SiO}_{2}$ Nanoparticles induced cytotoxicity by oxidative stress in human bronchial epithelial cell, Beas-2B. Environ Health Toxicol 26:e2011013. doi:10.5620/eht.2011.26. e2011013

Farcal LR, Uboldi C, Mehn D et al (2012) Mechanisms of toxicity induced by $\mathrm{SiO}_{2}$ nanoparticles of in vitro human alveolar barrier: effects on cytokine production, oxidative stress induction, surfactant proteins A mRNA expression and nanoparticles uptake. Nanotoxicology 7:1095-1110. doi:10.3109/17435390. 2012.710658

Fede C, Selvestrel F, Compagnin C et al (2012) The toxicity outcome of silica nanoparticles (Ludox??) is influenced by testing techniques and treatment modalities. Anal Bioanal Chem 404:1789-1802. doi:10.1007/s00216-012-6246-6

Fröhlich E, Samberger C, Kueznik T et al (2009) Cytotoxicity of nanoparticles independent from oxidative stress. J Toxicol Sci 34:363-375. doi: $10.2131 /$ jts.34.363

Fruijtier-Pölloth C (2012) The toxicological mode of action and the safety of synthetic amorphous silica-A nanostructured material. Toxicology 294:61-79. doi:10.1016/j.tox.2012.02.001

Fu PP, Xia Q, Hwang H-M et al (2013) Mechanisms of nanotoxicity: generation of reactive oxygen species. J Food Drug Anal. doi:10.1016/j.jfda.2014.01.005

Gehrke H, Frühmesser A, Pelka J et al (2013) In vitro toxicity of amorphous silica nanoparticles in human colon carcinoma cells. Nanotoxicology 7:274-293. doi:10.3109/17435390.2011.65220 7

Geys J, Nemery B, Hoet PHM (2010) Assay conditions can influence the outcome of cytotoxicity tests of nanomaterials: better assay characterization is needed to compare studies. Toxicol Vitr 24:620-629. doi:10.1016/j.tiv.2009.10.007
Glick D, Barth S, Macleod KF (2010) Autophagy: cellular and molecular mechanisms. J Pathol 221:3-12. doi:10.1002/path.2697. Autophagy

Gong C, Tao G, Yang L et al (2012) The role of reactive oxygen species in silicon dioxide nanoparticle-induced cytotoxicity and DNA damage in HaCaT cells. Mol Biol Rep 39:4915-4925. doi:10.1007/s11033-011-1287-z

Guichard Y, Fontana C, Chavinier E et al (2016) Cytotoxic and genotoxic evaluation of different synthetic amorphous silica nanomaterials in the V79 cell line. Toxicol Ind Health. doi: $10.1177 / 0748233715572562$

Guo C, Xia Y, Niu P et al (2015) Silica nanoparticles induce oxidative stress, inflammation, and endothelial dysfunction in vitro via activation of the MAPK/Nrf2 pathway and nuclear factor- $\kappa \mathrm{B}$ signaling. Int J Nanomedicine 10:1463-1477. doi:10.2147/IJN. S76114

Guo C, Yang M, Jing L et al (2016) Amorphous silica nanoparticles trigger vascular endothelial cell injury through apoptosis and autophagy via reactive oxygen species-mediated MAPK/Bcl-2 and PI3K/Akt/mTOR signaling. Int J Nanomed 11:5257-5276. doi:10.2147/IJN.S112030

Hara K, Shirasuna K, Usui F et al (2014) Interferon-tau attenuates uptake of nanoparticles and secretion of interleukin-1?? in macrophages. PLoS One 9:1-17. doi:10.1371/journal. pone. 0113974

Hashimoto M, Imazato S (2015) Cytotoxic and genotoxic characterization of aluminum and silicon oxide nanoparticles in macrophages. Dent Mater 31:556-564. doi:10.1016/j.dental.2015.02.009

Hassankhani R, Esmaeillou M, Tehrani AA et al (2014) In vivo toxicity of orally administrated silicon dioxide nanoparticles in healthy adult mice. Environ Sci Pollut Res. doi:10.1007/ s11356-014-3413-7

Hayashi Y, Miclaus T, Murugadoss S et al (2017) Female versus male biological identities of nanoparticles determine the interaction with immune cells in fish. Environ Sci Nano 4:895-906. doi:10.1039/C7EN00071E

Hofmann T, Schneider S, Wolterbeek A et al (2015) Prenatal toxicity of synthetic amorphous silica nanomaterial in rats. Reprod Toxicol 56:141-146. doi:10.1016/j.reprotox.2015.04.006

$\mathrm{Hu}$ YL, Gao JQ (2010) Potential neurotoxicity of nanoparticles. Int J Pharm 394:115-121. doi:10.1016/j.ijpharm.2010.04.026

Huang X, Li L, Liu T et al (2011) The shape effect of mesoporous silica nanoparticles on biodistribution. ACS Nano 5:5390 5399. doi:10.1021/nn200365a

Jose Corbalan J, Medina C, Jacoby A et al (2012) Amorphous silica nanoparticles aggregate human platelets: potential implications for vascular homeostasis. Int J Nanomed 7:631-639. doi:10.2147/IJN.S28293

Kasaai MR (2015) Nanosized particles of silica and its derivatives for applications in various branches of food and nutrition sectors. J Nanotechnol. doi:10.1155/2015/852394

Kasper J, Hermanns MI, Bantz C et al (2011) Inflammatory and cytotoxic responses of an alveolar-capillary coculture model to silica nanoparticles: comparison with conventional monocultures. Part Fibre Toxicol 8:6. doi:10.1186/1743-8977-8-6

Kasper JY, Feiden L, Hermanns MI et al (2015) Pulmonary surfactant augments cytotoxicity of silica nanoparticles: studies on an in vitro air-blood barrier model. Beilstein J Nanotechnol 6:517-528. doi:10.3762/bjnano.6.54

Khot LR, Sankaran S, Maja JM et al (2012) Applications of nanomaterials in agricultural production and crop protection: a review. Crop Prot 35:64-70. doi:10.1016/j. cropro.2012.01.007

Kim B, Kim H, Yu IJ (2014a) Assessment of nanoparticle exposure in nanosilica handling process: including characteristics 
of nanoparticles leaking from a vacuum cleaner. Ind Heal 52:152-162. doi:10.2486/indhealth.2013-0087

Kim J-H, Kim C-S, Ignacio RMC et al (2014b) Immunotoxicity of silicon dioxide nanoparticles with different sizes and electrostatic charge. Int J Nanomed 9(Suppl 2):183-193. doi:10.2147/IJN.S57934

Kim YR, Lee SY, Lee EJ et al (2014c) Toxicity of colloidal silica nanoparticles administered orally for 90 days in rats. Int $\mathbf{J}$ Nanomed 9:67-78. doi:10.2147/IJN.S57925

Lee S, Yun HS, Kim SH (2011) The comparative effects of mesoporous silica nanoparticles and colloidal silica on inflammation and apoptosis. Biomaterials 32:9434-9443. doi:10.1016/j.biomaterials.2011.08.042

Lee JA, Kim MK, Paek HJ et al (2014) Tissue distribution and excretion kinetics of orally administered silica nanoparticles in rats. Int J Nanomed 9:251-260. doi:10.2147/IJN.S57939

Lenz A-G, Karg E, Brendel E et al (2013) Inflammatory and oxidative stress responses of an alveolar epithelial cell line to airborne zinc oxide nanoparticles at the air-liquid interface: a comparison with conventional, submerged cell-culture conditions. Biomed Res Int 1:12

Leung CC, Yu ITS, Chen W (2012) Silicosis. Lancet 379:20082018. doi:10.1016/S0140-6736(12)60235-9

Li Y, Sun L, Jin M et al (2011) Size-dependent cytotoxicity of amorphous silica nanoparticles in human hepatoma HepG2 cells. Toxicol Vitr 25:1343-1352. doi:10.1016/j.tiv.2011.05.003

Li L, Liu T, Fu C et al (2015) Biodistribution, excretion, and toxicity of mesoporous silica nanoparticles after oral administration depend on their shape. Nanomed Nanotechnol Biol Med 11:1915-1924. doi:10.1016/j.nano.2015.07.004

Liang H, Jin C, Tang Y et al (2014) Cytotoxicity of silica nanoparticles on HaCaT cells. J Appl Toxicol 34:367-372. doi:10.1002/jat.2953

Liljenström C, Lazarevic D, Finnveden G (2013) Silicon-based nanomaterials in a life-cycle perspective, including a case study on self-cleaning coatings. ISBN 978-91-7501-942-0

Lison D, Thomassen LCJ, Rabolli V et al (2008) Nominal and effective dosimetry of silica nanoparticles in cytotoxicity assays. Toxicol Sci 104:155-162. doi:10.1093/toxsci/kfn072

Lison D, Vietti G, Van Den Brule S (2014) Paracelsus in nanotoxicology. Part Fibre Toxicol. doi:10.1186/s12989-014-0035-7

Lu X, Qian J, Zhou H et al (2011) In vitro cytotoxicity and induction of apoptosis by silica nanoparticles in human HepG2 hepatoma cells. Int J Nanomed 6:1889-1901. doi:10.2147/ IJN.S24005

Luyts K, Napierska D, Nemery B, Hoet PHM (2013) How physicochemical characteristics of nanoparticles cause their toxicity: complex and unresolved interrelations. Environ Sci Impacts 15:23-38. doi:10.1039/c2em30237c

Magdolenova Z, Collins A, Kumar A et al (2014) Mechanisms of genotoxicity. A review of in vitro and in vivo studies with engineered nanoparticles. Nanotoxicology 8:233-278. doi:10. 3109/17435390.2013.773464

Manke A, Wang L, Rojanasakul Y (2013) Mechanisms of nanoparticle-induced oxidative stress and toxicity. HINDAWI 2013:1-14. doi:10.1155/2013/942916

Maser E, Schulz M, Sauer UG et al (2015) In vitro and in vivo genotoxicity investigations of differently sized amorphous $\mathrm{SiO}_{2}$ nanomaterials. Mutat Res Genet Toxicol Environ Mutagen 794:57-74. doi:10.1016/j.mrgentox.2015.10.005

Maurer-jones MA, Lin Y, Haynes CL (2010) Functional assessment of metal oxide nanoparticle toxicity in immune cells. ACS Nano 4:3363-3373

McCracken C, Zane A, Knight DA et al (2013) Minimal intestinal epithelial cell toxicity in response to short- and long-term food-relevant inorganic nanoparticle exposure. Chem Res Toxicol 26:1514-1525. doi:10.1021/tx400231u

Mendoza A, Torres-Hernandez JA, Ault JG et al (2014) Silica nanoparticles induce oxidative stress and inflammation of human peripheral blood mononuclear cells. Cell Stress Chaperones 19:777-790. doi:10.1007/s12192-014-0502-y

Michael Berg J, Romoser AA, Figueroa DE et al (2013) Comparative cytological responses of lung epithelial and pleural mesothelial cells following in vitro exposure to nanoscale $\mathrm{SiO}_{2}$. Toxicol Vitr 27:24-33. doi:10.1016/j.tiv.2012.09.002

Morris AS, Adamcakova-Dodd A, Lehman SE et al (2016) Amine modification of nonporous silica nanoparticles reduces inflammatory response following intratracheal instillation in murine lungs. Toxicol Lett 241:207-215. doi:10.1016/j. toxlet.2015.11.006

Nabeshi H, Yoshikawa T, Matsuyama K et al (2011a) Amorphous nanosilica induce endocytosis-dependent ROS generation and DNA damage in human keratinocytes. Part Fibre Toxicol 8:1. doi:10.1186/1743-8977-8-1

Nabeshi H, Yoshikawa T, Matsuyama K et al (2011b) Systemic distribution, nuclear entry and cytotoxicity of amorphous nanosilica following topical application. Biomaterials 32:27132724. doi:10.1016/j.biomaterials.2010.12.042

Napierska D, Thomassen LCJ, Lison D et al (2010) The nanosilica hazard: another variable entity. Part Fibre Toxicol 7:39. doi:10.1186/1743-8977-7-39

Napierska D, Rabolli V, Thomassen LCJ et al (2012a) Oxidative stress induced by pure and iron-doped amorphous silica nanoparticles in subtoxic conditions. Chem Res Toxicol 25:828837. doi: $10.1021 / \mathrm{tx} 200361 \mathrm{v}$

Napierska D, Thomassen LCJ, Vanaudenaerde B et al (2012b) Cytokine production by co-cultures exposed to monodisperse amorphous silica nanoparticles: the role of size and surface area. Toxicol Lett 211:98-104. doi:10.1016/j. toxlet.2012.03.002

Nemmar A, Yuvaraju P, Beegam S et al (2015) In vitro platelet aggregation and oxidative stress caused by amorphous silica nanoparticles. Int J Physiol Pathophysiol Pharmacol 7:27-33

Nemmar A, Yuvaraju P, Beegam S et al (2016) Oxidative stress, inflammation, and DNA damage in multiple organs of mice acutely exposed to amorphous silica nanoparticles. Int $\mathrm{J}$ Nanomed. doi:10.2147/IJN.S92278

Nowak JS, Mehn D, Nativo P et al (2014) Silica nanoparticle uptake induces survival mechanism in A549 cells by the activation of autophagy but not apoptosis. Toxicol Lett 224:8492. doi:10.1016/j.toxlet.2013.10.003

Oberdörster G (2010) Safety assessment for nanotechnology and nanomedicine: concepts of nanotoxicology. J Intern Med 267:89-105. doi:10.1111/j.1365-2796.2009.02187.x

Oh S, Kim B, Kim H (2014) Comparison of nanoparticle exposures between fumed and sol-gel nano-silica manufacturing facilities. Ind Health 52:190-198. doi:10.2486/indhealth.2013-0117

Paek H-J, Chung H-E, Lee J-A et al (2014) Quantitative determination of silica nanoparticles in biological matrices and their pharmacokinetics and toxicokinetics in rats. Sci Adv Mater 6(6):1605-1610. doi:10.1166/sam.2014.1817

Pal AK, Bello D, Cohen J, Demokritou P (2015) Implications of in vitro dosimetry on toxicological ranking of low aspect ratio engineered nanomaterials. Nanotoxicology 9:871-885. doi: $10.3109 / 17435390.2014 .986670$

Panas A, Comouth A, Saathoff H et al (2014) Silica nanoparticles are less toxic to human lung cells when deposited at the airliquid interface compared to conventional submerged exposure. Beilstein J Nanotechnol 5:1590-1602. doi:10.3762/ bjnano.5.171 
Parveen A, Rizvi SHM, Sushma et al (2015) Intranasal exposure to silica nanoparticles induce alterations in pro-inflammatory environment of rat brain: involvement of oxidative stress. Toxicol Ind Health. doi: $10.1177 / 0748233715602985$

Passagne I, Morille M, Rousset M et al (2012) Implication of oxidative stress in size-dependent toxicity of silica nanoparticles in kidney cells. Toxicology 299:112-124. doi:10.1016/j. tox.2012.05.010

Rabolli V, Thomassen LCJ, Uwambayinema F et al (2011) The cytotoxic activity of amorphous silica nanoparticles is mainly influenced by surface area and not by aggregation. Toxicol Lett 206:197-203. doi:10.1016/j.toxlet.2011.07.013

Radomski A, Jurasz P, Alonso-Escolano D et al (2005) Nanoparticle-induced platelet aggregation and vascular thrombosis. $\mathrm{Br}$ J Pharmacol 146:882-893. doi:10.1038/sj.bjp.0706386

Rajendran P, Rengarajan T, Thangavel J et al (2013) The vascular endothelium and human diseases. Int J Biol Sci 9:1057-1069. doi:10.7150/ijbs.7502

Rajiv S, Jerobin J, Saranya V et al (2015) Comparative cytotoxicity and genotoxicity of cobalt (II, III) oxide, iron (III) oxide, silicon dioxide, and aluminum oxide nanoparticles on human lymphocytes in vitro. Hum Exp Toxicol. doi: $10.1177 / 0960327115579208$

Ryu HJ, Seong NW, So BJ et al (2014) Evaluation of silica nanoparticle toxicity after topical exposure for 90 days. Int $\mathbf{J}$ Nanomed 9:127-136. doi:10.2147/IJN.S57929

Sergent JA, Paget V, Chevillard S (2012) Toxicity and genotoxicity of nano- $\mathrm{SiO}_{2}$ on human epithelial intestinal HT-29 cell line. Ann Occup Hyg 56:622-630. doi:10.1093/annhyg/mes005

Shim KH, Jeong KH, Bae SO et al (2014) Assessment of $\mathrm{ZnO}$ and $\mathrm{SiO}_{2}$ nanoparticle permeability through and toxicity to the blood-brain barrier using evans blue and tem. Int J Nanomed 9:225-233. doi:10.2147/IJN.S58205

Smulders S, Luyts K, Brabants G et al (2014) Toxicity of nanoparticles embedded in paints compared with pristine nanoparticles in mice. Toxicol Sci 141:132-140. doi:10.1093/toxsci/ kfu112

Stern ST, Adiseshaiah PP, Crist RM (2012) Autophagy and lysosomal dysfunction as emerging mechanisms of nanomaterial toxicity. Part Fibre Toxicol 9:20. doi:10.1186/1743-8977-9-20

Sun L, Li Y, Liu X et al (2011) Cytotoxicity and mitochondrial damage caused by silica nanoparticles. Toxicol Vitr 25:16191629. doi:10.1016/j.tiv.2011.06.012

Tang L, Cheng J (2013) Nonporous silica nanoparticles for nanomedicine application. Nano Today 8:290-312. doi:10.1016/j. nantod.2013.04.007

Tavares AM, Louro H, Antunes S et al (2014) Genotoxicity evaluation of nanosized titanium dioxide, synthetic amorphous silica and multi-walled carbon nanotubes in human lymphocytes. Toxicol Vitr 28:60-69. doi:10.1016/j.tiv.2013.06.009

Tarantini A, Huet S, Jarry G et al (2015a) Genotoxicity of synthetic amorphous silica nanoparticles in rats following short-term exposure. Part 1: Oral route. Environ Mol Mutagen 56:218227. doi:10.1002/em.21935

Tarantini A, Lanceleur R, Mourot A et al (2015b) Toxicity, genotoxicity and proinflammatory effects of amorphous nanosilica in the human intestinal Caco-2 cell line. Toxicol Vitr 29:398407. doi:10.1016/j.tiv.2014.10.023

Thomassen LCJ, Rabolli V, Masschaele K et al (2011) Model system to study the influence of aggregation on the hemolytic potential of silica nanoparticles. Chem Res Toxicol 24:18691875. doi:10.1021/tx2002178

Turci F, Pavan C, Leinardi R et al (2016) Revisiting the paradigm of silica pathogenicity with synthetic quartz crystals: the role of crystallinity and surface disorder. Part Fibre Toxicol 13:32. doi:10.1186/s12989-016-0136-6
Uboldi C, Giudetti G, Broggi F et al (2012) Amorphous silica nanoparticles do not induce cytotoxicity, cell transformation or genotoxicity in Balb/3T3 mouse fibroblasts. Mutat Res Genet Toxicol Environ Mutagen 745:11-20. doi:10.1016/j. mrgentox.2011.10.010

Uemura E, Yoshioka Y, Hirai T et al (2016) Relationship between size and surface modification of silica particles and enhancement and suppression of inflammatory cytokine production by lipopolysaccharide- or peptidoglycan-stimulated RAW264.7 macrophages. J Nanoparticle Res 18:165. doi:10.1007/ s11051-016-3475-1

Van Der Zande M, Vandebriel RJ, Groot MJ et al (2014) Sub-chronic toxicity study in rats orally exposed to nanostructured silica. Part Fibre Toxicol 11:1-19. doi:10.1186/1743-8977-11-8

Vance ME, Kuiken T, Vejerano EP et al (2015) Nanotechnology in the real world: redeveloping the nanomaterial consumer products inventory. Beilstein J Nanotechnol 6:1769-1780. doi:10.3762/ bjnano.6.181

Voicu SNP, Dinu D, Sima C et al (2015) Silica nanoparticles induce oxidative stress and autophagy but not apoptosis in the MRC-5 cell line. Int J Mol Sci 16:29398-29416. doi:10.3390/ ijms 161226171

Vriens H, Mertens D, Regret R et al (2017) Chapter 11 case study III: the construction of a nanotoxicity databasethe MOD-ENP-TOX experience. Adv Exp Med Biol. doi:10.1007/978-3-319-47754-1

Wang F, Gao F, Lan M et al (2009) Oxidative stress contributes to silica nanoparticle-induced cytotoxicity in human embryonic kidney cells. Toxicol Vitr 23:808-815. doi:10.1016/j. tiv.2009.04.009

Wang W, Li Y, Liu X et al (2013) Multinucleation and cell dysfunction induced by amorphous silica nanoparticles in an L-02 human hepatic cell line. Int J Nanomed 8:3533-3541. doi:10.2147/IJN. S46732

Winkler HC, Suter M, Naegeli H (2016) Critical review of the safety assessment of nano-structured silica additives in food. J Nanobiotechnol 14:44. doi:10.1186/s12951-016-0189-6

Wittmaack K (2011) Novel dose metric for apparent cytotoxicity effects generated by in vitro cell exposure to silica nanoparticles. Chem Res Toxicol 24:150-158. doi:10.1021/tx100331w

Xie H, Wu J (2016) Silica nanoparticles induce alpha-synuclein induction and aggregation in PC12-cells. Chem Biol Interact 258:197-204. doi:10.1016/j.cbi.2016.09.006

$\mathrm{Xu}$ Z, Chou L, Sun J (2012) Effects of $\mathrm{SiO}_{2}$ nanoparticles on HFL-I activating ROS-mediated apoptosis via p53 pathway. J Appl Toxicol 32:358-364. doi:10.1002/jat.1710

Xue Y, Wu J, Sun J (2012) Four types of inorganic nanoparticles stimulate the inflammatory reaction in brain microglia and damage neurons in vitro. Toxicol Lett 214:91-98. doi:10.1016/j. toxlet.2012.08.009

Yang X, He C, Li J et al (2014a) Uptake of silica nanoparticles: neurotoxicity and Alzheimer-like pathology in human SK-N-SH and mouse neuro2a neuroblastoma cells. Toxicol Lett 229:240 249. doi:10.1016/j.toxlet.2014.05.009

Yang YX, Song ZM, Cheng B et al (2014b) Evaluation of the toxicity of food additive silica nanoparticles on gastrointestinal cells. $\mathrm{J}$ Appl Toxicol 34:424-435. doi:10.1002/jat.2962

Yang M, Jing L, Wang J et al (2016) Macrophages participate in local and systemic inflammation induced by amorphous silica nanoparticles through intratracheal instillation. Int J Nanomed 11:6217-6228

Ye Y, Liu J, Chen M et al (2010a) In vitro toxicity of silica nanoparticles in myocardial cells. Environ Toxicol Pharmacol 29:131137. doi:10.1016/j.etap.2009.12.002

Ye Y, Liu J, Xu J et al (2010b) Nano-SiO ${ }_{2}$ induces apoptosis via activation of p53 and Bax mediated by oxidative stress in human 
hepatic cell line. Toxicol Vitr 24:751-758. doi:10.1016/j. tiv.2010.01.001

Yoshida T, Yoshioka Y, Takahashi H et al (2014) Intestinal absorption and biological effects of orally administered amorphous silica particles. Nanoscale Res Lett. doi:10.1186/1556-276X-9-532

Yu T, Malugin A, Ghandehari H (2011) Impact of silica nanoparticle design on cellular toxicity and hemolytic activity. ACS Nano 5:5717-5728. doi:10.1021/nn2013904

Yu Y, Li Y, Wang W et al (2013) Acute toxicity of amorphous silica nanoparticles in intravenously exposed ICR mice. PLoS One. doi:10.1371/journal.pone.0061346

Yu Y, Duan J, Yu Y et al (2014) Silica nanoparticles induce autophagy and autophagic cell death in HepG2 cells triggered by reactive oxygen species. J Hazard Mater 270:176-186. doi:10.1016/j. jhazmat.2014.01.028

Yun J-W, Kim S-H, You J-R et al (2015) Comparative toxicity of silicon dioxide, silver and iron oxide nanoparticles after repeated oral administration to rats. J Appl Toxicol 35:681-693. doi:10.1002/jat.3125
Zhang XQ, Yin LH, Tang M, Pu YP (2011) ZnO, TiO(2), SiO(2, and $\mathrm{Al}(2) \mathrm{O}(3)$ nanoparticles-induced toxic effects on human fetal lung fibroblasts. Biomed Env Sci 24:661-669. doi:10.3967/0895-3988.2011.06.011

Zhang H, Dunphy DR, Jiang X et al (2012) Processing pathway dependence of amorphous silica nanoparticle toxicity: colloidal vs pyrolytic. J Am Chem Soc 134:15790-15804. doi:10.1021/ ja304907c

Zhang Q, Xu H, Zheng S et al (2015) Genotoxicity of mesoporous silica nanoparticles in human embryonic kidney 293 cells. Drug Test Anal 7:787-796. doi:10.1002/dta.1773

Zhang J, Ren L, Zou Y et al (2016) Silica nanoparticles induce start inhibition of meiosis and cell cycle arrest via down-regulating meiotic relevant factors. Toxicol Res 5:1453-1464. doi:10.1039/C6TX00236F

Zhuravskii S, Yukina G, Kulikova O et al (2016) Mast cell accumulation precedes tissue fibrosis induced by intravenously administered amorphous silica nanoparticles. Toxicol Mech Methods 26:260-269. doi:10.3109/15376516.2016.1169341 